\title{
Granzyme B-induced mitochondrial ROS are required for apoptosis
}

\author{
G Jacquemin ${ }^{1,5}$, D Margiotta ${ }^{1,5}$, A Kasahara ${ }^{1}$, EY Bassoy ${ }^{1}$, M Walch $^{2}$, J Thiery ${ }^{3}$, J Lieberman $^{4}$ and D Martinvalet ${ }^{\star 1}$
}

Caspases and the cytotoxic lymphocyte protease granzyme B (GB) induce reactive oxygen species (ROS) formation, loss of transmembrane potential and mitochondrial outer membrane permeabilization (MOMP). Whether ROS are required for GBmediated apoptosis and how GB induces ROS is unclear. Here, we found that GB induces cell death in an ROS-dependent manner, independently of caspases and MOMP. GB triggers ROS increase in target cell by directly attacking the mitochondria to cleave NDUFV1, NDUFS1 and NDUFS2 subunits of the NADH: ubiquinone oxidoreductase complex I inside mitochondria. This leads to mitocentric ROS production, loss of complex I and III activity, disorganization of the respiratory chain, impaired mitochondrial respiration and loss of the mitochondrial cristae junctions. Furthermore, we have also found that GB-induced mitocentric ROS are necessary for optimal apoptogenic factor release, rapid DNA fragmentation and lysosomal rupture. Interestingly, scavenging the ROS delays and reduces many of the features of GB-induced death. Consequently, GB-induced ROS significantly promote apoptosis.

Cell Death and Differentiation (2015) 22, 862-874; doi:10.1038/cdd.2014.180; published online 31 October 2014

To induce cell death, human granzyme B (GB) activates effector caspase-3 or acts directly on key caspase substrates, such as the proapoptotic $\mathrm{BH} 3$ only Bcl-2 family member Bid, inhibitor of caspase-activated DNase (ICAD), poly-(ADPribose) polymerase-1 (PARP-1), lamin B, nuclear mitotic apparatus protein 1 (NUMA1), catalytic subunit of the DNAdependent protein kinase (DNA-PKcs) and tubulin. ${ }^{1-3}$ Consequently, caspase inhibitors have little effect on human GB-mediated cell death and DNA fragmentation. ${ }^{2}$ GB causes reactive oxygen species (ROS) production, dissipation of the mitochondrial transmembrane potential $\left(\Delta \psi_{\mathrm{m}}\right)$ and MOMP, which leads to the release of apoptogenic factors such as cytochrome $c$ (Cyt $c$ ), HtrA2/Omi, endonuclease G (Endo G), Smac/Diablo and apoptosis-inducing factor, from the mitochondrial intermembrane space to the cytosol. ${ }^{4-11}$ Interestingly, cells deficient for Bid, Bax and Bak are still sensitive to human GB-induced cell death, ${ }^{5,11-13}$ suggesting that human GB targets the mitochondria in another way that needs to be characterized. Altogether, much attention has been focused on the importance of MOMP in the execution of GB-mediated cell death, leaving unclear whether ROS production is a bystander effect or essential to the execution of GBinduced apoptosis. The mitochondrial $\mathrm{NADH}$ : ubiquinone oxidoreductase complex $\mathrm{I}$ is a key determinant in steadystate ROS production. This $1 \mathrm{MDa}$ complex, composed of 44 subunits, ${ }^{14}$ couples the transfer of two electrons from NADH to ubiquinone with the translocation of four protons to generate the $\Delta \Psi \mathrm{m}$. The importance of ROS has been previously demonstrated for caspase-3 and granzyme A (GA) pathways through the cleavage of NDUFS1 and NDUFS3, respectively. ${ }^{15-18}$ GA induces cell death in a Bcl-2-insensitive and caspase- and MOMP-independent manner that has all the morphological features of apoptosis. ${ }^{1,16-20}$ As GA and GB cell death pathways are significantly different, whether ROS are also critical for GB still need to be tested. Here, we show that GB induces ROS-dependent apoptosis by directly attacking the mitochondria in a caspase-independent manner to cleave NDUFS1, NDUFS2 and NDUFV1 in complex I. Consequently, GB inhibits electron transport chain (ETC) complex I and III activities, mitochondrial ROS production is triggered and mitochondrial respiration is compromised. Interestingly, MOMP is not required for GB to cleave the mitochondrial complex I subunits and ROS production. Moreover, GB action on complex I disrupts the organization of the respiratory chain and triggers the loss of the mitochondrial cristae junctions. We also show that GB-mediated mitocentric ROS are necessary

${ }^{1} \mathrm{CMU}$, Cell Physiology and Metabolism, Faculté de Médecine, Université de Genève, Geneva, Switzerland; ${ }^{2}$ Unité d'Anatomie, Departement de Médecine, Université de Fribourg, Fribourg, Switzerland; ${ }^{3}$ INSERM U753, Gustave Roussy Cancer Campus, Villejuif, France and ${ }^{4}$ Program in Cellular and Molecular Medicine, Boston Children's Hospital, Harvard Medical School, Boston, MA, USA

${ }^{*}$ Corresponding author: D Martinvalet, CMU, Cell Physiology and Metabolism, Faculty of Medicine, University of Geneva, Rue Michel-Servet 1, Geneva 1211, Switzerland. Tel: +41 22379 5285; Fax: +41 2237952 60; E-mail: Denis.Martinvalet@ unige.ch

${ }^{5}$ These authors contributed equally to this work.

Abbreviations: $\Delta \Psi \mathrm{m}$, mitochondrial transmembrane potential; Bax, Bcl-2-associated X protein; Bcl-2, B-cell CLL/lymphoma 2; Bid, BH3-interacting domain death agonist; BNGE, blue native gel electrophoresis; Cyt c, cytochrome c; D, digitonin; Endo G, endonuclease G; ETC, electron transport chain; GA, granzyme A; GB, granzyme B; HAX-1, HCLS1-associated protein X-1; HBSS, Hank's balanced salt solution; HE, dihydroethidium; ICAD, inhibitor of caspase-activated DNase; LM, lauryl maltoside; MEF, mouse embryonic fibroblast; MnTBAP, Mn(III)tetrakis (4-benzoic acid) porphyrin; MOMP, mitochondrial outer membrane permeabilization; mtDNA, mitochondrial DNA; NAC, N-acetyl cysteine; NADH, nicotinamide adenine dinucleotide; NDUFA9/13, NADH dehydrogenase (ubiquinone) $1 \alpha$ subcomplex, 9/13; NDUFS1/2/ 3/7, NADH dehydrogenase (ubiquinone) Fe-S protein 1/2/3/7; NDUFV1, NADH dehydrogenase (ubiquinone) flavoprotein 1; NOX, NADPH oxidase; P, perforin; PARP, poly-(ADP-ribose) polymerase; PI, propidium iodide; PK, proteinase K; ROS, reactive oxygen species; SC, supercomplex; TPP, triphenylphosphonium; UQCRB, ubiquinolcytochrome $c$ reductase binding protein; UQCRC1/2, ubiquinol-cytochrome $c$ reductase core protein 1/2; UQCRFS1, ubiquinol-cytochrome $c$ reductase, Rieske iron-sulfur polypeptide 1; WB, western blot; WT, wild type

Received 27.5.14; revised 01.9.14; accepted 23.9.14; Edited by L Scorrano; published online 31.10.14 
for proper apoptogenic factor release from the mitochondria to the cytosol and for the rapid DNA fragmentation, both hallmarks of apoptosis. Moreover, GB-induced ROS are necessary for lysosomal membrane rupture. Thus, our work brings a new light to the GB pathway, showing that GB-mediated mitochondrial ROS are not adventitious waste of cell death, but essential mediators of apoptosis.

\section{Results}

GB disrupts complex I by cleaving NDUFV1, NDUFS2 and NDUFS1. To test whether ROS are necessary for GB rapid induction of cell death, K562 cells were treated with a sublytic concentration of perforin $(\mathrm{P})$ and $\mathrm{GB}$ in the presence or absence of the antioxidants $\mathrm{Mn}$ (III)tetrakis (4-benzoic acid) porphyrin (MnTBAP) or $\mathrm{N}$-acetyl cysteine (NAC). MnTBAP and NAC reduced both GB-induced mitochondrial ROS production and cell death in a dose-dependent manner as detected by MitoSOX and Annexin-propidium iodide (PI) staining, respectively (Figure 1a and Supplementary Figures 1a and b). MnTBAP also inhibits GB-induced ROS increase when detected with dihydroethidium $(\mathrm{HE})$ that reacts with total superoxide anion (Supplementary Figure 1c). Moreover, MnTBAP significantly protects the B-cell line 721.221 from YT-Indy human NK cell line that mainly abundantly expresses GB (Figure 1b), indicating that GB induces ROS-dependent apoptosis. The mitochondria-targeted ROS scavenger Mito $\mathrm{Q}^{21}$ completely scavenges $\mathrm{GB}$-induced ROS and inhibits cell death, suggesting that GB induces mitochondrial ROSdependent apoptosis (Figure 1c). By 2D gel electrophoresis and mass spectrometry analysis of the mitochondria treated or not with GB or GA, we identified NDUFV1 as a putative GB target (Figure 1d). The mass spectrometry data identified eight peptides covering more than $40 \%$ of NDUFV1 protein. NDUFV1 is a $51 \mathrm{kDa}$ iron-sulfur (Fe-S) cluster-containing subunit that catalyzes the initial transfer of electrons from NADH across complex I to ubiquinone, making it a good candidate target for GB-induced ROS. ${ }^{22-25} \mathrm{~GB}$ and $\mathrm{P}$ treatment of $\mathrm{K} 562$ cells induced a dose- and time-dependent cleavage of NDUFV1 comparable to PARP-1 cleavage (Figure 1e). The caspase inhibitors z-VAD-fmk and DEVD-fmk have a partial effect, whereas the GB inhibitor Ac-IETD-CHO prevented NDUFV1 cleavage. Using CutDB and SitePrediction bioinformatics tool, ${ }^{26,27}$ we found that $G B$ has predicted cleavage sites for NDUFV1, NDUFS2, NDUFS1, NDUFS3, NDUFS7 and NDUFA13. Similar to NDUFV1, both NDUFS1 and NDUFS2 were cleaved in K562 cells treated with $\mathrm{GB}$ and $\mathrm{P}$ similarly to PARP-1 (Figure $1 \mathrm{f}$ and data not shown). GB cleavage of NDUFS1 and NDUFS2 was slightly affected by z-VAD-fmk (Supplementary Figure 1d and data not shown). The dose of Z-VAD used was effective as it inhibits caspase cleavage of PARP (89 kDa fragment) and prevents caspase-3 autoprocessing from p19 to p17 (Supplementary Figure 1d). Tagged complex I subunits overexpressed in the B-cell line 721.221, or MEF localized to the mitochondria and integrated into complex I (Supplementary Figures 1e-g and data not shown). GB induced a dose- and time-dependent cleavage of tagged NDUFV1, NDUFS2 and NDUFS1 similar to PARP-1 and HAX $-1^{11,12}$ cleavage (Supplementary Figures $2 \mathrm{a}-\mathrm{c}$ ). GB did not cleave NDUFS3, NDUFS7 or NDUFA13 (data not shown). Tagged NDUFV1, NDUFS2 and NDUFS1 were also cleaved when 721.221 cells were incubated with YT-Indy (Figures 1g-i). Moreover, the caspase-3-uncleavable mutant of NDUFS1 (D255A-NDUFS1) was also cleaved, confirming that it is a direct GB substrate (Figure 1h). In the presence of cycloheximide that inhibits protein synthesis and de novo complex I production, GB and $\mathrm{P}$ still cleave complex I subunits, indicating that GB is acting on fully assembled complex I (Supplementary Figure 2d). ${ }^{28-30}$ NDUFS3 and NDUFA9 complex I subunits not cleaved by GB were still present long after the cells had died following $4 \mathrm{~h}$ of $\mathrm{GB}$ treatment (Supplementary Figure 2e). Altogether, GB, independently of caspases, cleaves NDUFV1, NDUFS2 and NDUFS1 in cells undergoing killer cell attack.

GB cleaves recombinant NDUFV1, NDUFS1 and NDUFS2 and cleaves these proteins in intact mitochondria. CutDB predicts that GB will cleave NDUFV1 after D118 and D338/340 (Supplementary Figure 3a), NDUFS1 after D364 (Supplementary Figure 3b) and NDUFS2 after D317 (Supplementary Figure 4). These cleavage site sequences are conserved between mice and humans. The cleavage fragment sizes corresponded roughly to predicted cleavage sites. The $\mathrm{D}-\mathrm{A}$ mutations at the predicted cleavage sites protect from GB, confirming that NDUFV1, NDUFS1 and NDUFS2 are direct GB substrates. In isolated intact mitochondria, GB cleaved all three of these complex I subunits, but not NDUFS3 or NDUFA13, within $1 \mathrm{~min}$ (Figure 2a). The cleavage of the subunits was inhibited by valinomycin-mediated mitochondrial $\Delta \Psi \mathrm{m}$ loss, suggesting that GB needs an intact $\Delta \psi_{\mathrm{m}}$ to reach its substrates inside the mitochondrial matrix.

GB-induced ROS are mediated by complex I subunits cleavage, are independent of caspase activation and potentiate cell death. Overexpression of GB-uncleavable forms of complex I subunits (triple mutant) significantly reduced and slowed down GB-mediated ROS production, compared with cells overexpressing the wild-type (WT) substrates (triple WT) (Figures 2b-d). Thus, mitochondrial complex I proteolysis is a major contributor to ROS generation in this pathway. The presence of endogenous NDUFV1, NDUFS2 and NDUFS1 might account for some residual ROS production. However, the silencing of these endogenous subunits in triple mutant cells triggers spontaneous ROS production (data not shown). Overexpression of these uncleavable mutant proteins also significantly inhibited and slowed down GB-mediated cell death (Figures $2 e$ and f). GB-mediated ROS production and cell death in triple WT and triple mutant cells was caspase-independent (Figures $2 \mathrm{~g}$ and h). Thus, GB induces mitocentric ROS by cleaving NDUFV1, NDUFS2 and NDUFS1 independently of caspases to promote apoptosis.

GB cleaves complex I subunits independently of MOMP. Purified mitochondria were treated with $\mathrm{GB}$ in the presence or absence of S100 cytosolic fraction as a source of Bid, and 
a
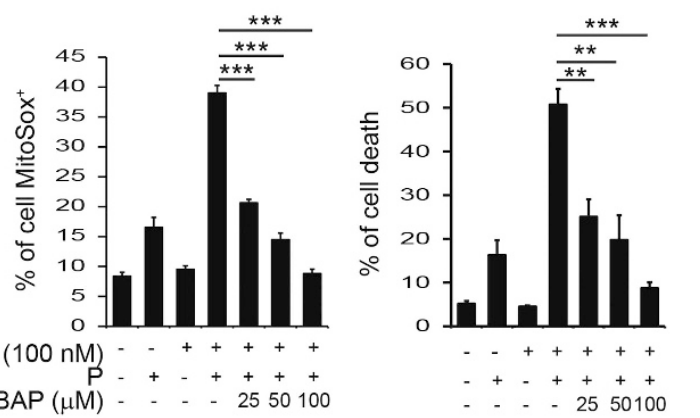

\section{c}
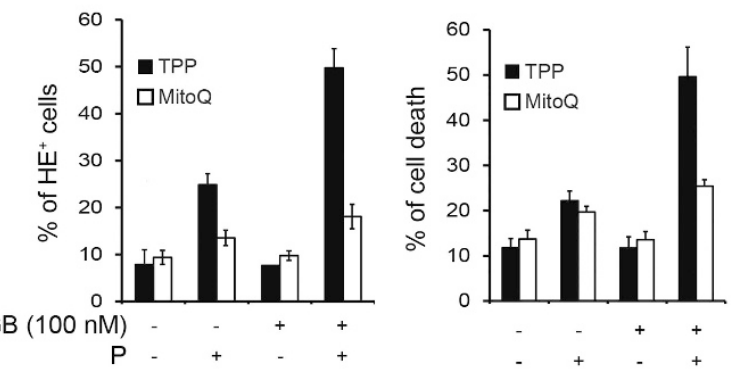

e

$\begin{array}{r}\mathrm{GB}(\mathrm{nM}) \\ \mathrm{P}\end{array}-\mathrm{-}-\mathrm{+} \quad 45050150450150150150150150150$

AC-IETD-CHO

ZVAD+DEVD

$\begin{array}{lllllllllllll}\text { Time (min) } & 60 & 60 & 60 & 60 & 60 & 60 & 60 & 60 & 5 & 15 & 30 & 60\end{array}$

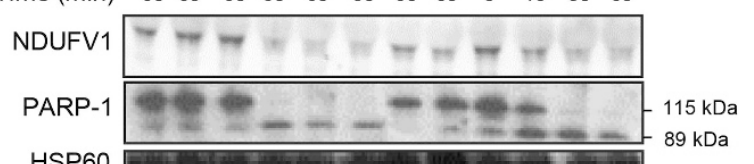

HSP60 -

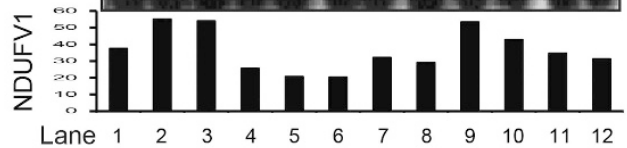

g

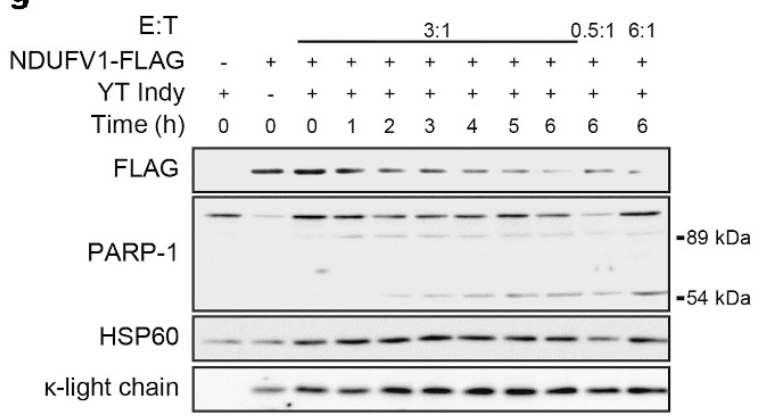

b

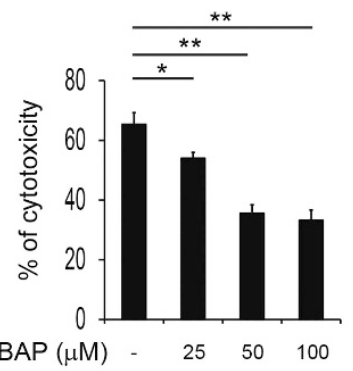

d

NDUFV1
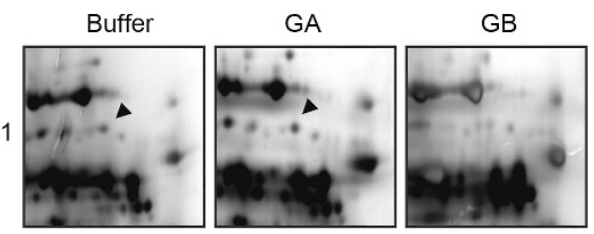

f

GB (nM) - - $400400400400400-50100200400$ Time (min) $60 \quad 605 \quad 15 \quad 30 \quad 601206060 \quad 60 \quad 60 \quad 60$

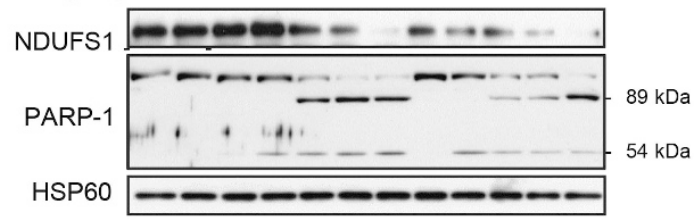

h

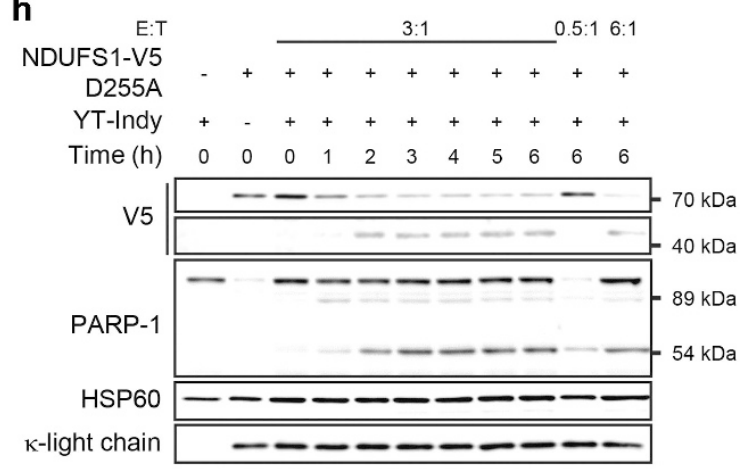

i

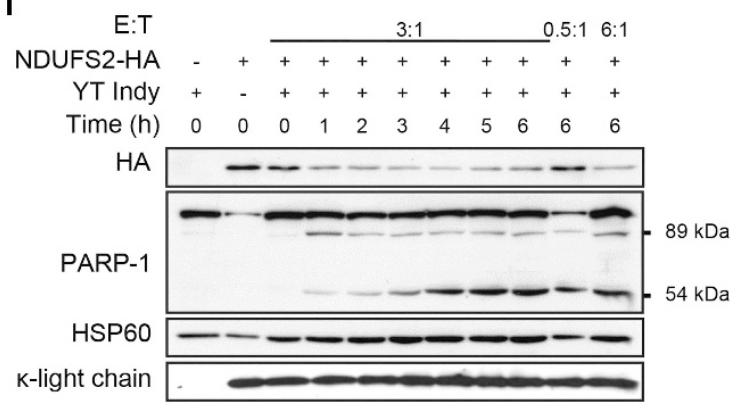


a

$\begin{array}{rcccccccc}\text { Time (min) } & 5 & 5 & 5 & 5 & 5 & 1 & 5 & 5 \\ \text { Valinomycin } & - & - & - & - & - & - & - & + \\ \text { GB (nM) } & - & 450 & 50 & 150 & 450 & 450 & 450 & 450 \\ \text { Mito } & + & - & + & + & + & + & + & + \\ & & & & & & & \\ \text { NDUFS1 } \\ \text { NDUFS2 } \\ \text { NDUFV1 }\end{array}$

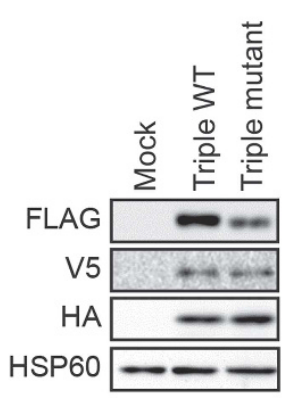

C

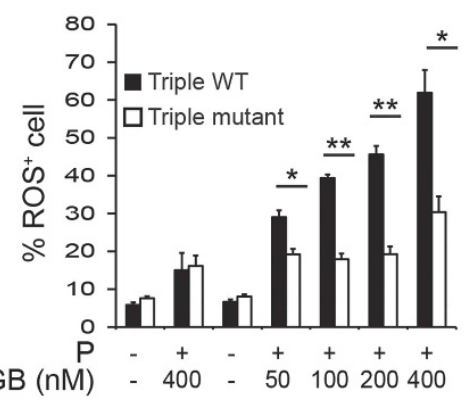

d

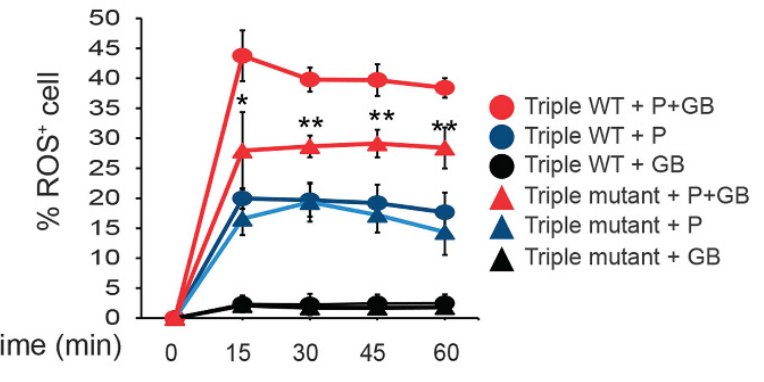

e

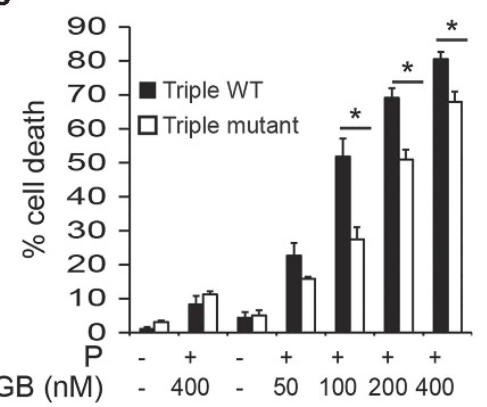

f

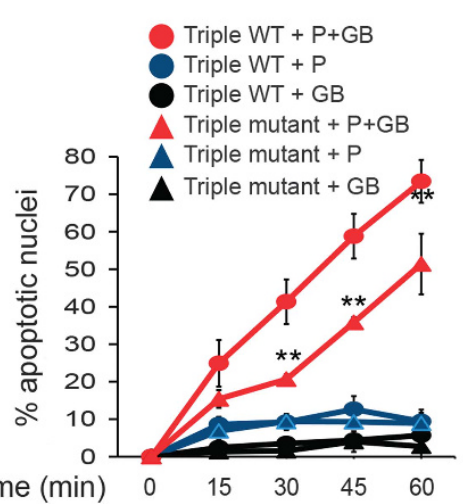

g

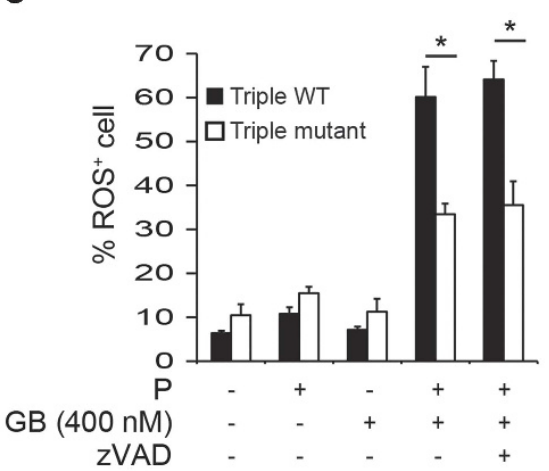

h

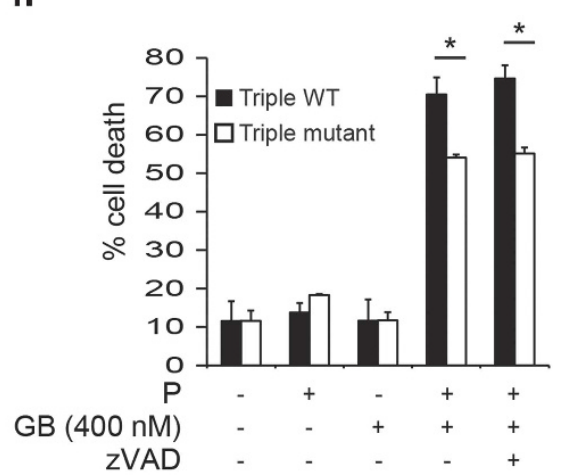

Figure 2 Overexpression of GB-uncleavable NDUFS1, NDUFS2 and NDUFV1 protects against GB-induced ROS production and cell death. (a) Purified intact mouse liver mitochondria, pretreated or not with valinomycin, were incubated with GB and probed for complex I subunits. (b) Expression of WT (triple WT) and GB-uncleavable NDUFV13xFLAG, NDUFS2-HA and NDUFS1-V5 (triple mutant) proteins in untransfected or transfected K562 cells. (c-h) Transfected K562 cells were treated with P \pm GB as indicated and assessed for mitochondrial ROS by MitoSOX staining and flow cytometry ( $\mathbf{c}, \mathbf{d}$ and $\mathbf{g}$ ) and for cell death by Annexin V-PI staining and flow cytometry (e and $\mathbf{h}$ ) or counting of apoptotic nuclei stained by Hoechst 33342 (f, mean of at least 300 nuclei per conditions, from three independent experiments). P+GB (red lines), P alone (blue lines), GB alone (black lines), triple WT (circles) and triple mutant (triangles). In ( $\mathbf{g}$ and $\mathbf{h}$ ), cells were pretreated or not with z-VAD-fmk to inhibit caspases. Mean \pm S.E.M. of at least three independent experiments is shown, ${ }^{*} P<0.05$ and ${ }^{* *} P<0.01$

Figure 1 GB cleaves complex I subunits NDUFS1, NDUFV1 and NDUFS2. (a) K562 cells pretreated or not for $1 \mathrm{~h}$ with MnTBAP were treated with $\mathrm{P} \pm \mathrm{GB}$ as indicated. ROS (MitoSOX+, left panel) and cell death (Annexin V-Pl, right panel) were monitored at 10 and $45 \mathrm{~min}$, respectively. (b) The 721.221 target cells preincubated or not with MnTBAP for $1 \mathrm{~h}$ were mixed with YT-Indy effector cells expressing only GB at an E/T ratio of $12: 1$. Target cell killing was monitored by calcein release assay. (c) K562 cells preincubated for $1 \mathrm{~h}$ with $20 \mu \mathrm{M}$ of the mitochondria-targeted antioxidant MitoQ or decyl-TPP as a control were treated with $\mathrm{P} \pm \mathrm{GB}$ as indicated. ROS (dihydroethidium positive (HE+), left panel) and cell death (Annexin V-PI, right panel) were monitored after 10 and $45 \mathrm{~min}$, respectively. (a-c) Mean \pm S.E.M. of at least three independent experiments, ${ }^{* \star} P<0.01$ and ${ }^{* \star *} P<0.001$. (d) Close-up of $2 \mathrm{D}$ isoelectric focusing (IEF) SDS-PAGE gels of purified intact mouse liver mitochondria treated or not with GB or GA. The spot indicated by the arrow was identified as NDUFV1 by mass spectrometry. (e and f) K562 cells, treated with $\mathrm{P} \pm \mathrm{GB}$ as indicated, were analyzed by immunoblot probed for NDUFV1 (e) and NDUFS1 (f), PARP-1 and Hsp60. Some cells were pretreated for 30 min with the caspase inhibitors Z-Val-Ala-Asp-fluoromethylketone (z-VAD-fmk) and Z-Asp-Glu-Val-Asp-fluoromethylketone (DEVD-fmk) or with the GB-specific inhibitor Ac-lle-Glu-Thr-Asp-CHO (Ac-IETD-CHO). NDUFV1 bands quantification in the lower panel (e) was measured with the ImageJ software (National Institutes of Health, Bethesda, MD, USA). (g-i) The 721.221 target cells, transfected with tagged NDUFV1 (g), caspase-3-uncleavable D255A-NDUFS1 (h) or NDUFS2 (i) were treated with YT-Indy NK cells at indicated effector/target $(E / T)$ ratios and probed for the ectopically expressed complex I proteins using anti-tag antibodies. Experiments in (e-i) were repeated at least three times with similar results 
apoptogenic factors release was followed to assess MOMP. $^{4,6-10}$ GB induced Cyt $c$ and Endo G release only in the presence of $\mathrm{S} 100$ (Figure $3 \mathrm{a}$ ), whereas cleavage of NDUFS1 occurred in the absence of S100 (Figure 3a). Interestingly, NDUFS1 cleavage was increased in the presence of S100, most likely as the result of the combined action of GB and caspase-3. Moreover, GB still induces ROS and cell death in Bax- and Bak-deficient mouse embryonic fibroblasts (MEFs), ${ }^{31}$ although to a lower extent compared with the WT counterpart (Figures $3 b-d$ ). Note that the level of GB-induced ROS corresponds to the extent of cell death following $\mathrm{GB}$ treatment of $\mathrm{Bax}^{-1-}$ and $\mathrm{Bak}^{-1-} \mathrm{MEF}$. The higher level of ROS observed in WT MEF could be because of the combined action of GB and caspase-3 on complex I subunits cleavage as observed in Figure 3a. GB cleaved tagged NDUFV1, NDUFS2 and NDUFS1 similarly in WT and $\mathrm{Bax}^{-1-} / \mathrm{Bak}^{-/-}$MEFs (Figures $3 e$ and f). Thus, GB induces complex I subunit cleavage and ROS independently of MOMP. Therefore, GB does not need the opening of the mitochondrial outer membrane generated by the MOMP to enter the mitochondria and to cleave complex I subunits.

GB-induced ROS are necessary for apoptogenic factor release and oligonucleosomal DNA fragmentation. ROS have been shown to enhance apoptogenic factor release. $^{32-34}$ Interestingly, although NAC did not alter GB-induced Bid cleavage, NAC reduced and delayed the release of Cyt $c$, Endo $\mathrm{G}$ and Smac triggered by GB (Figures $4 a-c)$. Moreover, neither NAC nor MitoQ prevents GB cleavage of complex I subunits (Supplementary Figure 5a). Similarly, triple mutant cells experienced GB-mediated Bid cleavage while they are resistant to GB-induced apoptogenic factor release (Figures $4 \mathrm{~d}-\mathrm{f}$ ). We obtained similar results when Cyt $c$ distribution was assessed by immune staining following $G B$ and $P$ treatment of triple mutant K562 cells (Figure 4g). Thus, GB-mediated mitocentric ROS also promote the release of apoptogenic factors.

Moreover, the well-characterized GB-mediated DNA fragmentation $^{35,36}$ was reduced and delayed by NAC treatment (Figures $4 \mathrm{~h}$ and i). In a similar manner, triple mutant cells were also resistant to GB-induced DNA fragmentation (Figure 4j). Neither NAC nor overexpression of GB-uncleavable complex I subunits inhibits GB-induced ICAD cleavage (data not shown). Altogether, this indicates that GBmediated mitocentric ROS are also required for oligonucleosomal DNA fragmentation.

GB-induced ROS are necessary for lysosomal membrane rupture. Mitochondrial ROS have been implicated in lysosomal disruption in tumor necrosis factor-mediated cell death. ${ }^{35}$ Lysosomal green staining began to decline in a

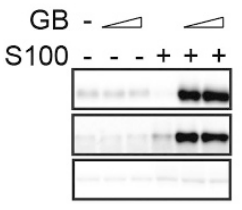

Supernatant b

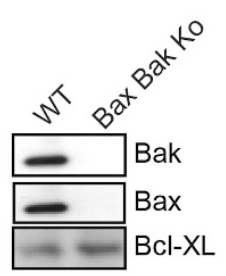

Pellet

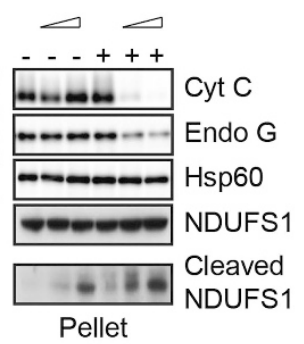

e

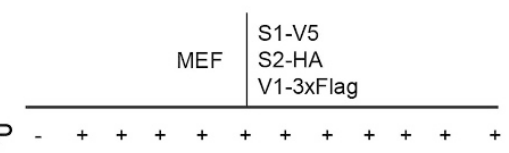

C

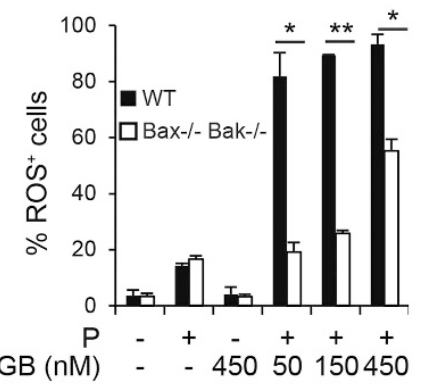

d

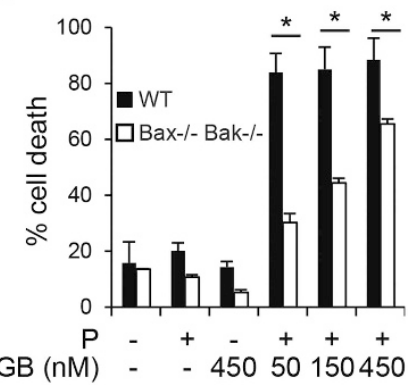

f

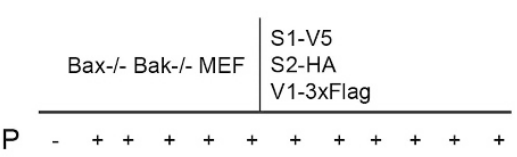

$\mathrm{GB}(\mathrm{nM}) \quad-\quad-400400400400400-1050200400$

Time (min) $0 \begin{array}{llllllllllll}0 & 5 & 15 & 30 & 60 & 120 & 60 & 60 & 60 & 60 & 60\end{array}$

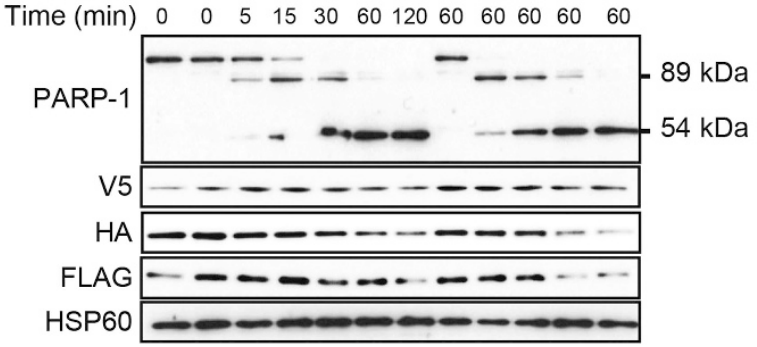

Figure 3 GB cleaves NDUFS1, NDUFV1 and NDUFS2 independently of MOMP. (a) Cyt $c$ and Endo G release and NDUFS1 cleavage were assessed by immunoblot of supernatants and mitochondrial pellets from purified intact mouse liver mitochondria treated with 50 and $450 \mathrm{nM}$ of GB in the presence or absence of $S 100$ cytosolic fraction. Hsp60 was probed as a loading control protein that is not released. (b) Bax ${ }^{-1}$ Bak $^{-1-}$ MEF do not express Bax or Bak as assessed by immunoblot. (c and d) ROS production (c) and cell death (d) assessed by MitoSOX and Annexin V-PI staining, respectively, in WT and Bax ${ }^{-1-}$ Bak $^{-1-}$ MEFs treated with GB and P for $1 \mathrm{~h}$. Mean \pm S.E.M. of three independent experiments is shown, ${ }^{*} P<0.05$ and ${ }^{* *} P<0.01$. (e and f) WT (e) and $\mathrm{Bax}^{-/-} \mathrm{Bak}^{-1-}$ (f) MEFs overexpressing NDUFS1-V5, NDUFV1-3xFLAG and NDUFS2-HA were treated with GB and P as indicated and probed for NDUFS1, NDUFV1 and NDUFS2 using anti-tag antibodies. PARP-1 was probed as a control for GB activity and Hsp60 is a loading control. Blots are representative of at least three independent experiments 
a

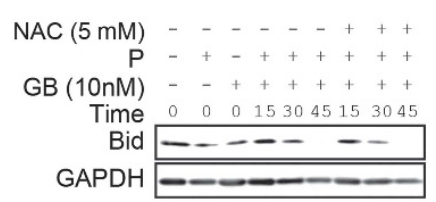

d

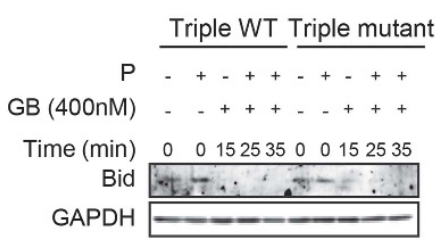

b

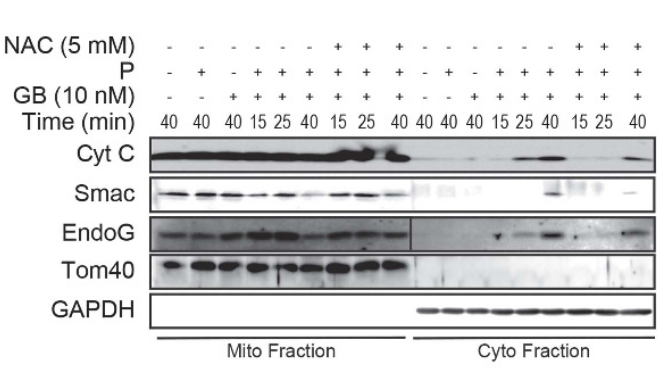

e

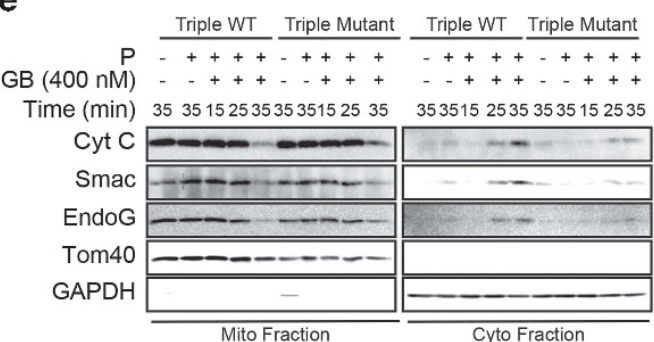

h

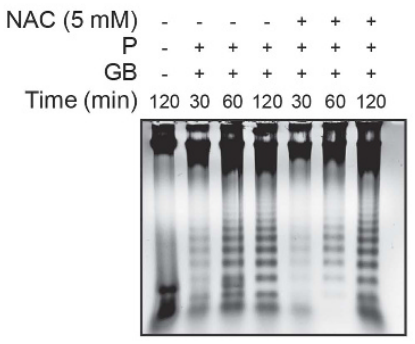

c

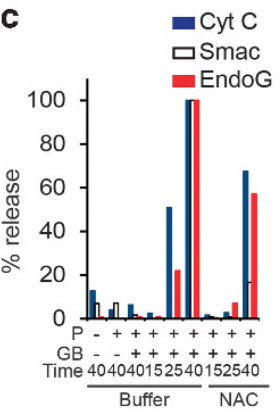

f

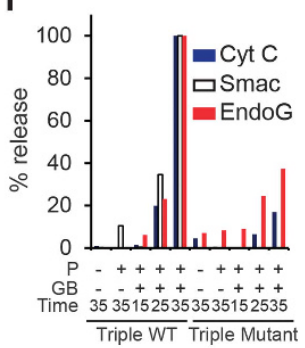

i

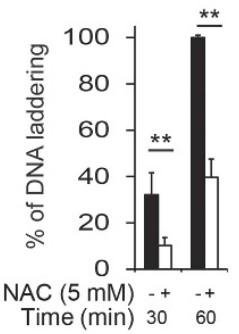

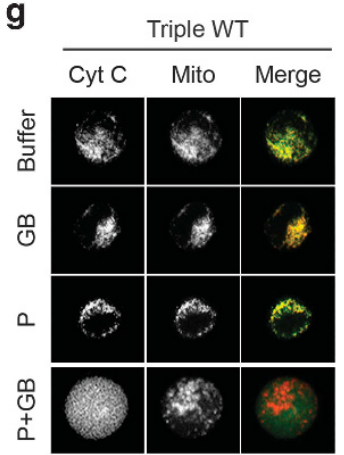

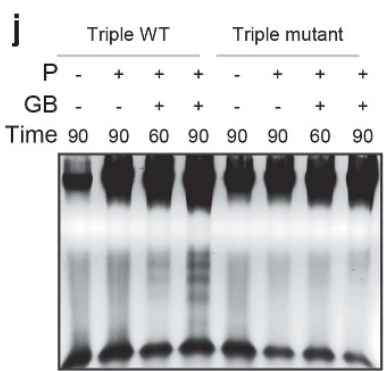

Triple Mutant

\begin{tabular}{|c|c|c|}
\hline Cyt C & Mito & Merge \\
\hline 80 & 89 & 87 \\
\hline * & $x^{\circ}$ & $x^{\prime}$ \\
\hline s & $x$ & 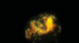 \\
\hline d & के & के \\
\hline
\end{tabular}

$\mathbf{k}$

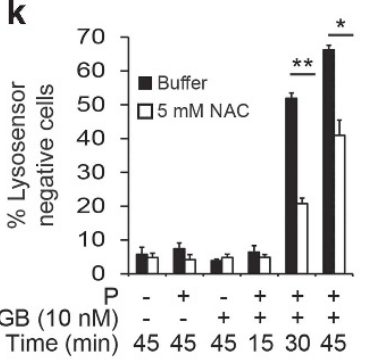

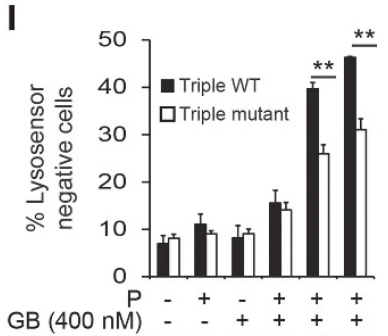

Time (min) 606060304560

Figure 4 GB-induced ROS are required for proper apoptogenic factor release, DNA laddering and lysosomal membrane permeabilization. (a) Total cell lysate, (b) cytosolic (cyto) and mitochondrial (mito) fractions of U937 cells treated or not with P and GB, with or without NAC pretreatment were analyzed by WB for Bid cleavage and the release of Cyt c, Smac and Endo G from the mitochondria. Tom 40 and GAPDH were probed as loading controls and to verify proper fractionation. (c) Quantification of the percentage of Cyt $c$, Endo G and Smac release from panel b. (d and e) K562 stably expressing WT (triple WT) or GB-uncleavable (triple mutant) NDUFV1, NDUFS1 and NDUFS2 were treated as in (a) to assess Bid cleavage or as in (b) for the release of the apoptogenic factors. (f) Quantification of the percentage of Cyt $c$, Endo $\mathrm{G}$ and Smac release from panel $\mathrm{e}$. (g) Immunostaining for Cyt c of Mitotracker deep red-loaded K562 triple WT and triple mutant treated or not with GB and P for 30 min. (h and i) DNA from U937 cells, treated as in (a), was analyzed by agarose gel electrophoresis (and the \% of DNA that migrated below $3 \mathrm{~kb}$ was quantified. (h) A representative gel and (i) the mean \pm S.E.M. of three independent experiments. ${ }^{*} P<0.01$. (j) K562 triple WT or triple mutant cells were treated and analyzed as in (h). A representative gel of three independent experiments is shown. (k) U937 cells treated as indicated with or without $5 \mathrm{mM} \mathrm{NAC}$ were stained with a Lysosensor, which only fluoresces in lysosomes that maintain acidic pH. Mean \pm S.E.M. of three independent experiments. ${ }^{*} P<0.05$ and ${ }^{* \star} P<0.01$. (I) K562 cells overexpressing triple WT or triple mutant complex I subunits were treated and analyzed as in (k)

U937 cells within 30 min of GB+P treatment, as an indication of $\mathrm{pH}$ rises in compromised lysosomes, suggesting that lysosomal permeabilization is a feature of GB-mediated death (Figure 4k and Supplementary Figure 5b). The loss of lysosensor green staining was significantly inhibited by NAC. Moreover, overexpression of GB-uncleavable complex I subunits reduced lysosomal membrane permeabilization, suggesting that GB-induced mitocentric ROS are also 
necessary for this late event of apoptosis (Figure $4 \mathrm{l}$ and Supplementary Figure 5c).

GB-induced ROS requires a functional respiratory chain. It has been proposed that GB induces ROS, independently of mitochondria, by a caspase-dependent activation of the NADPH oxidases (NOX). ${ }^{36}$ However, here z-VAD-fmk had no significant effect on GB-induced ROS production and cell death, and overexpression of the uncleavable complex I subunits markedly reduced ROS generation by GB (Figures $2 c, d$ and $g$ ). The $\rho^{0} \mathrm{~K} 562$ cells that have a significant loss of mitochondrial DNA (mtDNA), no respiration and no complexes I and III (Figure $5 \mathrm{a})^{37}$ are completely resistant to GBinduced ROS and cell death (Figures $5 \mathrm{~b}$ and c). Interestingly, GB still induced ROS and cell death in $N O X 1^{-I-}$ or $N O X 4^{-I-}$ MEFs (Figures $5 d$ and e). As MEF does not express NOX1 and as GB induces the same level of ROS from the NOX1 KO and the NOX4 KO, we conclude that in our system the NOX contribution in GB-induced ROS and cell death is marginal relative to the mitochondrial contribution.

GB lacks a mitochondrial targeting sequence. Furthermore, cleavage of NDUFV1, NDUFS2 and NDUFS1 was MOMPindependent, suggesting that permeabilization of the outer membrane is not needed. We verified that $G B$ enters the mitochondria by flow cytometry and western blot (WB) analysis of isolated mitochondria incubated with Alexa Fluor647-labeled or -unlabeled GB followed by gentle proteinase $\mathrm{K}$ (PK) treatment to remove externally bound proteins. GB mitochondrial import was inhibited by valinomycin (Figures $5 f$ and $\mathrm{g}$ ). Valinomycin, which also disrupted the $\Delta \Psi \mathrm{m}$ of intact cells (Figure $5 \mathrm{~h}$ ) without altering $\mathrm{P}$-mediated GB uptake into cells (Figure 5i), inhibited GB-induced ROS and cell death (Figures 5j and k). Taken together, these results show that GB requires a functional respiratory chain and intact transmembrane potential to enter the mitochondria and induce ROSdependent cell death.

GB disrupts complex I and III activities. GB treatment rapidly reduced both the glutamate/malate- and succinatedependent respiration of isolated mitochondria with kinetics similar to complex I cleavage (Figures $6 a$ and b). Interestingly, when purified intact mitochondria were treated with GB and respiratory complexes were analyzed by blue native gel electrophoresis (BNGE), ${ }^{38,39}$ GB induced a dose-dependent inhibition of complex I activity that was significant within 1 min as monitored by in-gel activity assay (Figure 6c). Unexpectedly, GB also rapidly inhibited complex III activity, whereas the activities of complexes IV and V were unaffected. Using spectrophotometric assay of mitochondria treated with GB, we confirmed that GB alters complex I and III activities, although complex IV function was untouched (Supplementary Figures 6a, c and d). Moreover, GB also had a mild effect on complex II activity (Supplementary Figure $6 b)$. Despite the change in complex III function, GB did not cleave the complex III subunits UQCRC1, UQCRC2 and UQCRFS1, whereas mild effect was seen on UQCRB at the highest dose of GB (Figure $6 \mathrm{~d}$ ). Thus, GB rapidly inhibits complex I, II and III activity and reduces mitochondrial respiration.
GB alters the organization of the mitochondrial respiratory chain. Mitochondrial ETC complexes organize into supercomplexes (SCs) that channel electrons in response to changes in substrate availability. ${ }^{28}$ The alteration in complex III activity we measured might be because of changes in SC formation caused by GB cleavage of complex I subunits. In lauryl maltoside (LM)-solubilized mitochondria, which preserves monomeric ETC complexes but disrupts SCs, GB reduced NDUFV1, NDUFS2 and NDUFS1, but had no effect on the complex III proteins UQCRC1, UQCR2 or UQCRS1 (Figure 6e). In digitonin (D)-solubilized mitochondria, which preserved both monomeric complexes and SCs, $\mathrm{I}+\mathrm{III}_{2}$ SC formation was greatly enhanced by GB treatment, which was more evident when probing for unaffected NDUFA13 and NDUFS3 (Figure 6g). We did not observe SC I+III2+IV probably because the mitochondria were purified from C57B6 mice that are deficient for Cox7a2l (Cyt $c$ oxidase subunit VIla polypeptide 2 like) and therefore cannot have III+IV association (Supplementary Figure 6e). ${ }^{28}$ GB induced a significant loss in monomeric complex I and III activities, as shown previously (Figures $6 \mathrm{c}$ and $\mathrm{f}$ ). In D-solubilized samples, complex I and III activities of $\mathrm{SC} I+\mathrm{III}_{2}$ were not significantly changed by $\mathrm{GB}$, even though much more SC was formed after GB treatment, indicating that the specific activity of these complexes was reduced by GB treatment. Thus, GB alters mitochondrial respiratory chain organization by tilting the balance from monomeric complexes to an accumulation of $\mathrm{SC} \mathrm{I}+\mathrm{III}_{2}$.

GB triggers loss of mitochondrial cristae junctions. Cristae morphology is a critical determinant of ETC organization and respiratory efficiency. ${ }^{40}$ We therefore examined whether GB treatment might also affect the shape of cristae. By electron microscopy, we observed that in GB-treated mitochondria many of the cristae appeared to have lost their junction (Figures $6 \mathrm{~h}$ and i). A better appreciation and the functional significance of GB-induced cristae disorganization will require further studies. Thus, GB has a profound effect on mitochondrial respiration, respiratory complex activity and mitochondrial morphology.

\section{Discussion}

Here we show for the first time that GB directly cleaves NDUFV1, NDUFS2 and NDUFS1 in ETC complex I, independently of caspases, to trigger mitocentric ROS-dependent apoptosis. GB-mediated cleavage of complex I subunits not only generates ROS but also has a profound effect on mitochondrial function. GB alters complex I, II and III function and disrupts mitochondrial respiration of metabolites that feed into either complex I or complex II, disrupts ETC supramolecular organization and causes cristae to detach. The generation of mitochondrial ROS in the form of superoxide, the species produced by complex I dysfunction, ${ }^{41}$ was previously shown to be necessary for killer lymphocyte-mediated death since superoxide scavengers virtually completely inhibit death. ${ }^{17,42}$ Here we further show that GB-mediated mitocentric ROS are necessary for optimal apoptogenic factor release, pointing out that factor release need two independent steps, (1) the permeabilization of the mitochondrial outer 
a

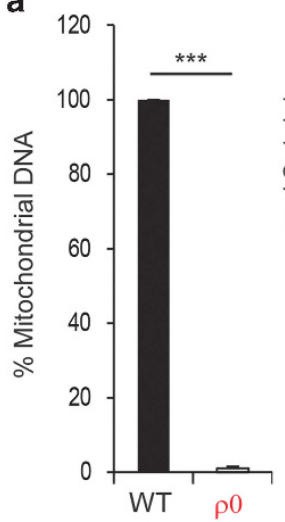

d

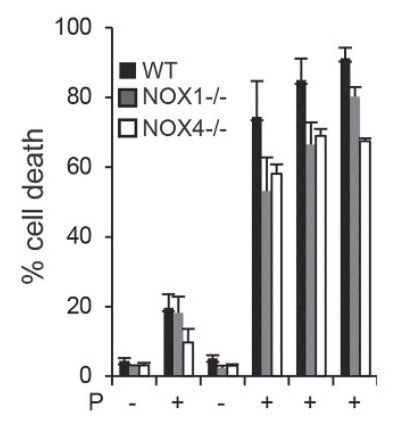

GB (nM) - - 40050150400
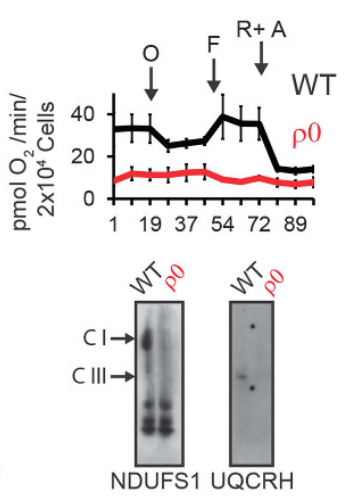

e

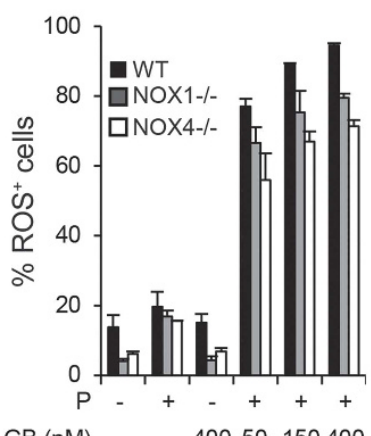

b

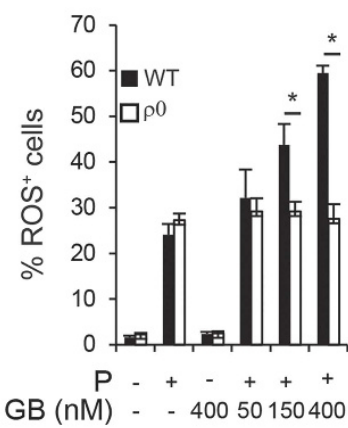

f c

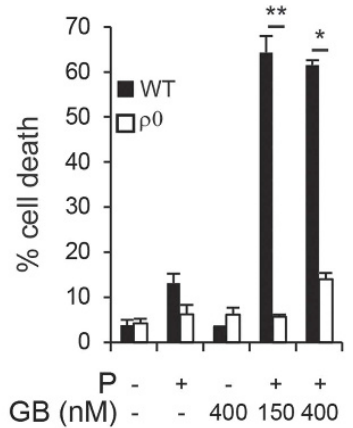

h

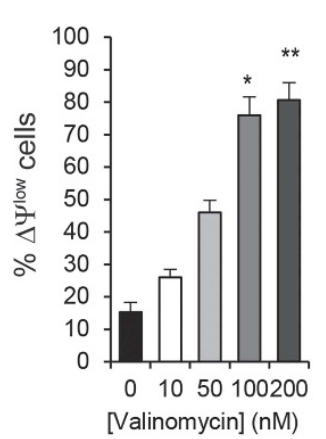

i

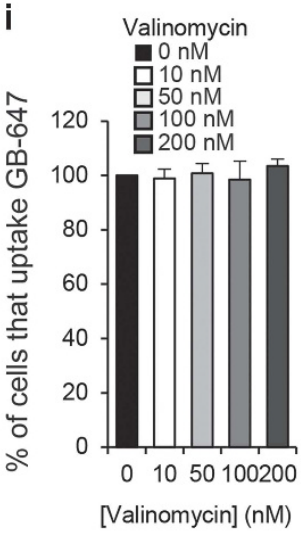

j

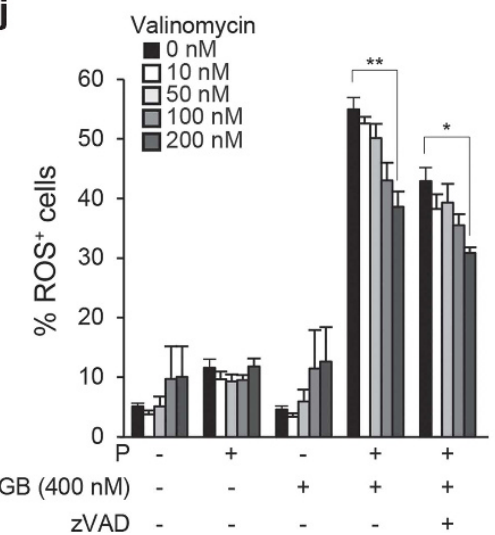

k

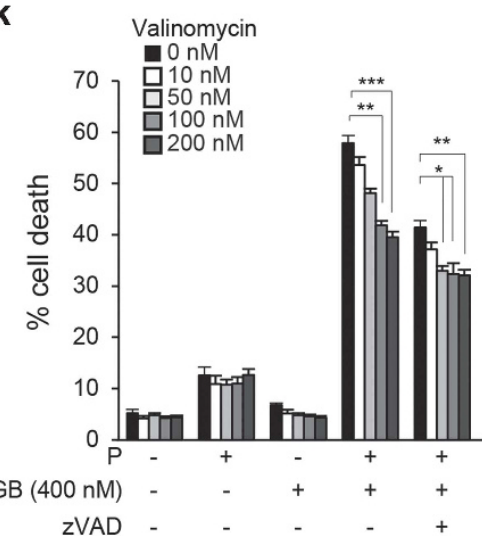

Figure 5 GB-induced ROS generation and cell death require mitochondrial respiration. (a) Quantification of mitochondrial DNA in WT and $\rho^{0}$ K562 cells as measured by qPCR amplification of representative genes (left panel). Oxygen consumption rate of WTand $\rho^{0} \mathrm{~K} 562$ cells assessed by seahorse measurement (top right panel) $(0$, oligomycin; F, FCCP; R, rotenone; A, antimycin). Analysis of complexes I and III from WTand $\rho^{0} \mathrm{~K} 562$ cells by blue native gel and WB (bottom right panel). There is a complete loss of mtDNA and complexes I and III in $\rho^{0} \mathrm{~K} 562$ cells and they do not respire. (b and c) $\rho^{0} \mathrm{~K} 562$ cells are highly resistant to GB-induced ROS production (b), assessed by MitoSOX staining, and cell death (c), assessed by Annexin V-PI staining. (d and e) WT, NOX1 ${ }^{-1-}$ and NOX4 ${ }^{-1-}$ MEFs were treated with P+GB and analyzed as above for ROS production (d) and cell death (e). (f) Purified intact mouse liver mitochondria treated or not with valinomycin were incubated with Alexa-647 GB before partial treatment with PK to remove externally bound proteins and analyzed by FACS. (g) Same as in (f) using unlabeled GB and analyzed by immunoblot. (h-k) Although valinomycin treatment of K562 cells depolarizes mitochondria (h), it has no effect on GB uptake into cells assessed by flow cytometry (i). Valinomycin inhibits GB-induced ROS (j) and cell death (k) in a dose-dependent manner, even in the presence of the pancaspase inhibitor $z-V A D$. The color code for valinomycin concentrations is as in (h). All graphs show mean \pm S.E.M. of at least four independent experiments. ${ }^{*} P<0.05,{ }^{* \star} P<0.01$ and ${ }^{* \star *} P<0.001$

membrane following GB cleavage of Bid, which trigger Bax/ Bak oligomerization and MOMP, (2) ROS that untether the apoptogenic factors within the intermembrane space for their release into the cytosol. Mitocentric ROS are also required for proper oligonucleosomal DNA fragmentation. This is in agreement with the fact that Endo G release is ROS- dependent, knowing that Endo G synergize with CAD for DNA fragmentation. Interestingly, NAC does not prevent GB-mediated ICAD cleavage (data not shown). We have reported that ROS were necessary for the SET complex containing GA-activated DNAses (three prime repair exonuclease 1 and nm23-H1) nuclear translocation upon 


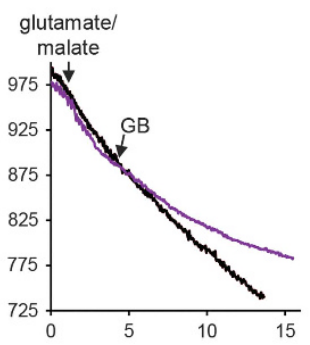

b

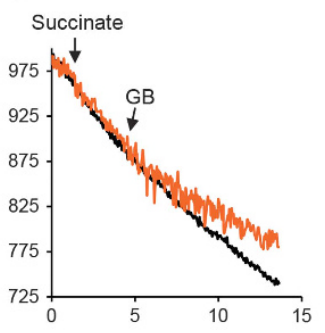

c

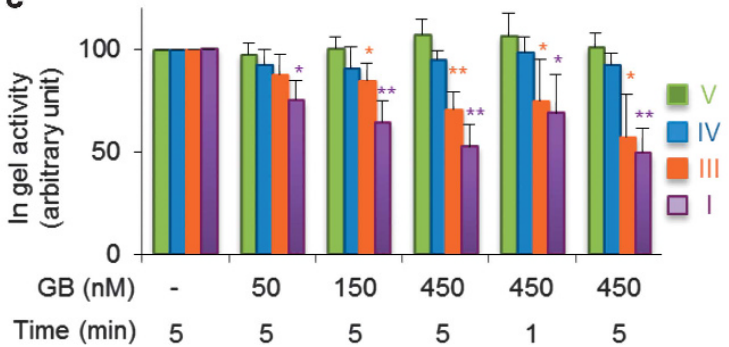

d

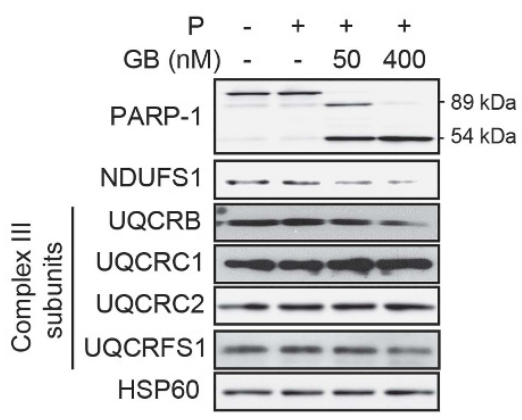

e

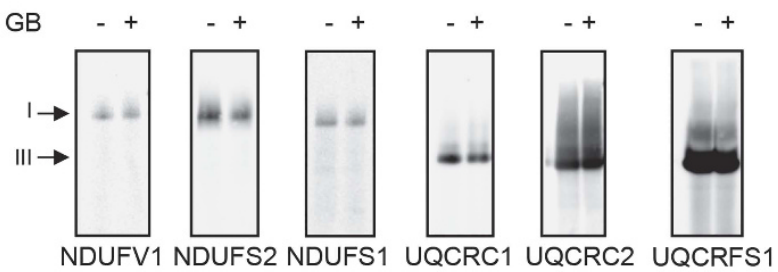

g

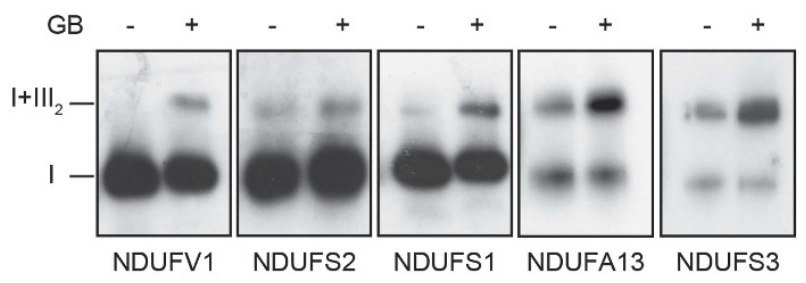

f

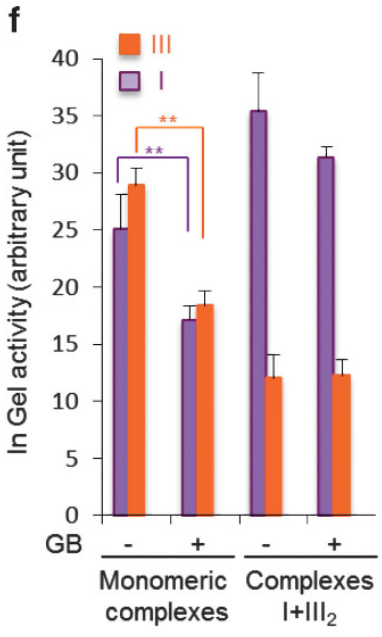

h

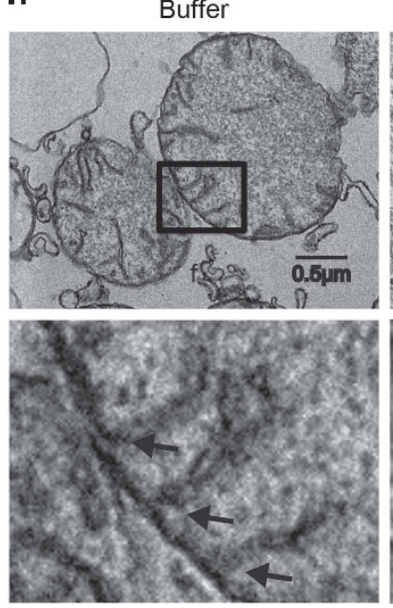

GB

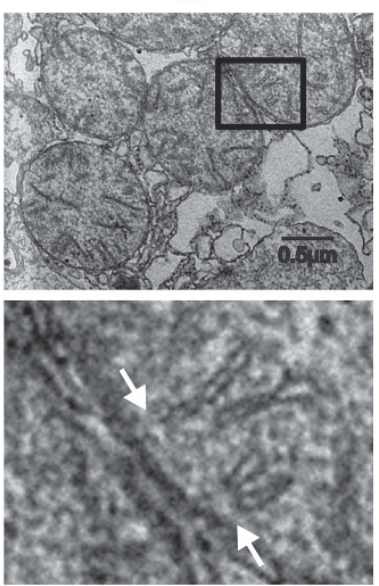

i

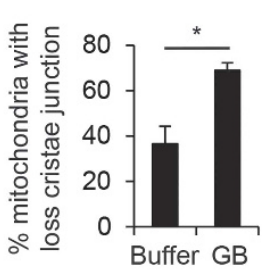

Figure 6 GB disrupts complex I and III activity. (a and $\mathbf{b})$ Purified mouse liver mitochondria in respiration buffer were stimulated with glutamate/malate (a) or succinate (b) and $\mathrm{O}_{2}$ consumption was measured using a Clark electrode. Within $1 \mathrm{~min}$ of GB treatment, respiration of GB-treated mitochondria (purple and orange lines) was reduced compared with untreated mitochondria (black lines). Data are representative of at least three independent experiments. (c) Purified mitochondria were treated with GB as indicated. Monomeric mitochondrial respiratory complexes were solubilized using LM and resolved by BNGE before measuring in-gel ETC complex activities. Mean \pm S.E.M. of three independent experiments is shown. ${ }^{*} P<0.05$ and ${ }^{\star *} P<0.01$. (d) The 721.221 cells, treated with GB and P, were probed for complex III proteins. The GB substrates NDUFS1 and PARP-1 were probed as positive controls and $\mathrm{Hsp} 60$ as a loading control. Blots are representative of at least three independent experiments. (e-g) Isolated liver mitochondria treated with $450 \mathrm{nM} \mathrm{GB}$ for 5 min were solubilized with LM to resolve monomeric complexes (e) or D to preserve SCs (g) and analyzed by BNGE and immunoblot. Blots are representative of at least four independent experiments. (f) Complex I and III in-gel activity was monitored in monomeric complexes after LM solubilization and I+III2 SC after D solubilization. Shown are mean \pm S.E.M. of four independent experiments. ${ }^{* \star} P<0.01$. (h) Representative electron micrographs after C57B6 mouse liver mitochondria were treated with buffer or GB. GB treatment triggers loss of mitochondrial cristae junctions. White arrows indicate detached cristae, whereas black arrows show attached cristae. (i) The proportion of mitochondria with detached cristae was quantified and represented as the mean \pm S.E.M. of three independent experiments is shown. ${ }^{*} P<0.05$ and ${ }^{* *} P<0.01$

GA-induced cell death. ${ }^{16,17}$ It is possible that in a similar manner, ROS are required for the nuclear translocation of $\mathrm{CAD}$ and Endo $\mathrm{G}$. Additional work will be required to test this possibility. Moreover, ROS damage the integrity of the lysosomal compartment, probably following redox modification of proteins and lipids of this compartment.

GA, caspase-3 and now GB proteolyzed subunits of complex I to induced ROS-dependent apoptosis, ${ }^{15,16}$ making 
complex I a point of crosstalk for three distinct cell death pathways. We have recently found that granzymes are delivered into bacteria to cleave multiple components of bacterial complex I to generate ROS-dependent bacteria death. ${ }^{43}$ Thus, complex I disruption and ROS production are conserved biochemical mechanisms important for executing programmed cell death in two evolutionary kingdoms.

Our results indicate that GB must enter the mitochondrial matrix to cleave its substrates in the matrix-protruding arm of complex I. How does GB (or for that matter GA and caspase-3), which lack mitochondrial targeting sequences, get into the mitochondrial matrix is still unknown. GB mitochondrial entry does not require MOMP, but does require an intact $\Delta \Psi \mathrm{m}$. As MOMP dissipates the $\Delta \Psi_{\mathrm{m}}$, GB may only enter the mitochondria that have not undergone MOMP or before MOMP dissipates the $\triangle \Psi \mathrm{m}$.

GB-induced ROS required mitochondrial electron flow as $\rho^{0}$ K562 cells were resistant to both GB-induced ROS and cell death. This result and our finding that ROS generation is caspase-independent differ from a previous work, ${ }^{36}$ which implicated NOX oxidases in ROS generation by GB. However, we found that GB generation of ROS and cell death were not significantly reduced in $N O X 1^{-1-}$ or NOX $4^{-/-}$MEFs, suggesting that mitochondria rather than NOX proteins are the primary source of ROS in GB cell death pathway.

Based on the crystal structure of Thermus thermophilus complex I, mammalian NDUFV1, NDUFV2 and NDUFS1 are predicted to be localized at the tip of the matrix-protruding arm of complex I, exposed to solvent ${ }^{30,44}$ and hence be accessible to $\mathrm{GB}$. We found that complex I within $\mathrm{SC} \mathrm{I}+\mathrm{III}_{2}$ is also altered by $\mathrm{GB}$. This is consistent not only with the function of those subunits in forming the electron entry site but also with the topology of $\mathrm{SC} \mathrm{I}+\mathrm{II}_{2}$ as dimeric complex III associates with the membrane segment of complex I, leaving the matrixprotruding arm free. ${ }^{45,46}$

Cleavage of NDUFS1, NDUFS2 and NDUFV1 would be expected to disrupt complex I function and favor a leakage of the electrons to produce ROS. GB unexpectedly inhibited complex III activity and succinate-dependent respiration. We did not observe cleavage of tested complex III subunits, except a mild effect on UQCRB. It is possible that GB also acts on other complex III subunits we did not evaluate. Moreover, GB has a mild effect on complex II activity. This plus the increased $\mathrm{SC} \mathrm{I}+\mathrm{II}_{2}$ formation may help explain why GB compromises respiration of the complex II substrate succinate. Taken together, it appears that GB hits multiple site of the respiratory chain at the level of complex I, II and complex III that will alter the electron flow and favor the formation of mitocentric ROS.

In intact complex I, the Fe-S centers and their associated electrons are buried in the protein part of the subunits to shield them from ambient $\mathrm{O}_{2}$. $\mathrm{GB}$, by cleaving these subunits close to their Fe-S centers (Supplementary Figures 3 and 4), may expose electrons within the Fe-S centers to ambient oxygen allowing their direct reaction to form superoxide. Reverse electron transport accounts for most $\mathrm{O}_{2}^{-}$production by complex I under basal conditions in a process that involves reduced ubiquinone. ${ }^{47,48}$ NDUFS2 establishes a groove with NDUFS7 to form the ubiquinone binding site. ${ }^{23-25} \mathrm{~GB}$ cleavage of NDUFS2 may alter the ubiquinone binding site to favor ROS production in the reverse electron transfer mode.
In our model, electron flow is required for GB to induce ROS. Yet, GB cleavage of NDUFV1 might shorten the forward electron supply at a very early stage. One possibility to explain continuous electron flow and ROS production in this pathway is by the SC organization of the respiratory chain that allows reverse electron flow. GB treatment increases SC $\mathrm{I}+\mathrm{II}_{2}$ organization. In this setting, reverse flowing electrons might then leak at the level of damaged complex I to produce ROS. In addition, we cannot exclude that the effect of GB on other complexes, for example, complex II and III might also contribute to the ROS production. Mitochondrial cristae morphology also influences respiratory chain organization. ${ }^{40,49}$ GB disrupts cristae junctions through an unknown mechanism, which likely contributes to mitochondrial dysfunction and ROS production.

Taken together, our results demonstrate that GB-induced respiratory chain complexes disruption triggers ROS production that is necessary for apoptosis.

\section{Materials and Methods}

Antibodies. Anti-V5 (V5-10) and anti-FLAG (M2) (Sigma-Aldrich, St. Louis, MO, USA); anti-PARP (H-250), anti-Hsp60 (H-300), anti-tubulin (B-7), anti-Tom40 and anti-HAX-1 (FL-279) (Santa Cruz Biotechnology, Dallas, TX, USA); anti-HA (3F10) (Roche Diagnostics (Schweiz AG), Rotkeuz, Switzerland); anti- $\kappa$-light-chain-HRP (Bethyl Laboratories, Inc., Montgomery, TX, USA); anti-NDUFS1 and anti-NDUFS2 (Epitomics, Abcam, Burlingame, CA, USA); anti-Tom20 and anti-Cyt $c$ (BD Biosciences, San Jose, CA, USA); anti-NDUFV1 (Aviva Systems Biology, San Diego, CA, USA); anti-NDUFS3 (3F9DD2) (Invitrogen, Life Technologies, Grand Island, NY, USA); anti-NDUFS7 (Acris, Herford, Germany; AP21286PU-N); NDUFS13 (Mitosciences, Eugene, OR, USA; MS103); anti-CORE1/UQCRC1 (MS303), anti-CORE2/UQCRC2 (MS304) and anti-UQCRFS1 (MS305) (Abcam); anti-Endo G (Novus Biological, Littleton, CO, USA); anti-caspase-3 (3G2) and antihistone H3 (Cell Signaling).

P and GB treatment. P was purified from the rat RNK-16 cells and GB from the human YT-Indy NK cells. ${ }^{50} \mathrm{~GB}$ was first added to cells $\left(5 \times 10^{4}\right)$ suspended in $30 \mu \mathrm{l}$ cell buffer (Hank's balanced salt solution (HBSS) with $10 \mathrm{mM} \mathrm{HEPES,} \mathrm{pH} \mathrm{7.4,}$ $0.4 \% \mathrm{BSA}, 4 \mathrm{mM} \mathrm{CaCl}$ ) and immediately thereafter an equal volume of $\mathrm{P}$ in HBSS with $10 \mathrm{mM}$ HEPES, $\mathrm{pH} 7.4$, was added. The $\mathrm{P}$ concentration was chosen as the sublytic concentration that lyses $5-15 \%$ of cells. Cells were incubated at $37^{\circ} \mathrm{C}$ for the indicated time. In some cases, cells were preincubated with $100 \mu \mathrm{M}$ of the caspase inhibitors z-VAD-fmk+DEVD-fmk or $100 \mu \mathrm{M}$ of the GB inhibitor Ac-IETD$\mathrm{CHO}$ for 30 min at $37^{\circ} \mathrm{C}$ before $\mathrm{P}$ and $\mathrm{GB}$ treatment. When antioxidants were used, cells were pretreated with $\mathrm{N}$-acetyl-L-cysteine (Sigma-Aldrich) for $1 \mathrm{~h}$ or with MnTBAP (Calbiochem) for $30 \mathrm{~min}$ before the addition of $\mathrm{P}$ and GB. For the mitochondria-targeted antioxidant MitoQ, cells were preincubated for $1 \mathrm{~h}$ with $20 \mu \mathrm{M}$ of MitoQ (kindly provided by Dr. Mike Murphy from the Mitochondrial Biology Unit, MRC UK, Cambridge, UK) or $20 \mu \mathrm{M}$ of decyl-TPP (triphenylphosphonium) as a control, before treatment with $\mathrm{P}$ and $\mathrm{GB}$.

Measurement of apoptosis, ROS production and $\Delta \Psi \mathrm{m}$. Treated cells were washed in PBS and stained with Annexin V Alexa Fluor-647 and PI (Life Technologies) to detect apoptotic cells. Alternatively, cells were fixed with $0.5 \%$ paraformaldehyde in PBS and nuclei were stained with $5 \mu \mathrm{g} / \mathrm{ml} \mathrm{Hoechst} 33342$ (Molecular Probes, Life Technologies) and analyzed by microscopy. Condensed or fragmented nuclei were considered as apoptotic. For each individual experiment, at least 300 nuclei were counted per condition. For detection of ROS, cells were stained with $5 \mu \mathrm{M}$ MitoSOX or $2 \mu \mathrm{M} \mathrm{HE}$ (Life Technologies) for $5 \mathrm{~min}$ at room temperature (RT) and analyzed by flow cytometry. To assess $\Delta \Psi \mathrm{m}$, cells were labeled with $500 \mathrm{nM}$ tetramethylrhodamine, methyl ester for $15 \mathrm{~min}$ at RT and washed three times in PBS before flow cytometry analysis with an Accuri C6 flow cytometer (BD Biosciences)

Site-directed mutagenesis. pCMV6 vectors containing NDUFS1, NDUFS2 and NDUFV1 cDNA sequences were purchased from OriGene Technologies (Rockville, MD, USA). Site-directed mutagenesis was performed by polymerase 
chain reaction with Herculase II Fusion DNA Polymerase (Agilent Technologies, Santa Clara, CA, USA) using overlapping primers, followed by restriction digest with Dpnl. PCR products were transformed into One Shot TOP10 Competent Escherichia coli (Life Technologies).

The following primers were used $\left(5^{\prime}-3^{\prime}\right)$ : S1D255A forward, GACAGAATCCATT GATGTAATGGCTGCGGTTGGAAG and S1D255A reverse, CTTCCAACCGCAGC CATTACATCAATGGATTCTGTC; S1D364A forward, GAGTGGACTCTGCCACCT TATGCACTGAAG and S1D364A reverse, CTTCAGTGCATAAGGTGGCAGAGTC CACTC; S2D317A forward, CGACCAGGTTGAGTTTGCTGTTCCTGTTGGTTCTC and S2D317A reverse, GAGAACCAACAGGAACAGCAAACTCAACCTGGTCG; and V1D118A forward, TGGTGAACGCAGCCGAGGGGGAGCC and V1D118A reverse, GGCTCCCCCTCGGCTGCGTTCACCA and V1D338/340A forward, CGGTGCTG ATGGCCTTCGCTGCGCTGGTGCA; V1D338/340A reverse, TGCACCAGCGCA GCGAAGGCCATCAGCACCG.

Generation of stable cell lines. Retroviral vectors were obtained by subcloning the CDNA sequence of human NDUFS1, NDUFS2 or NDUFV1 into pQCXIH, pQCXIP or pQCXIN (Takara, Clontech, Mountain View, CA, USA), respectively. The following primers were used $\left(5^{\prime}-3^{\prime}\right)$ : V1 forward, AAAAAATTAAT TAAGCCACCATGCTGGCAACACGGCGGC and V1 reverse (3xFLAG tag), forward, AAAAATTAATTAACTACTTGTCATCGTCATCCTTGTAGTCGATGTCATGATCTTTAT AATCACCGTCATGGTCTTTGTAGTCAGAGGCAGCCTGCCGGGC; S1, AAAAAAG CGGCCGCGCCACCATGTTAAGGATACCTGTAAGAAAG and S1 reverse (V5 tag), AAAAAAGGATCCTCACGTAGAATCGAGACCGAGGAGAGGGTTAGGGATAGGCTT ACCGCATATGGATGGTTCCTCTAC; S2 forward, AAAAAAGCGGCCGCGCCACCAT GGCGGCGCTGAGGGCTTTG and S2 reverse (HA tag), TGCTTCTGAATTCT CAAGCGTAGTCTGGGACGTCGTATGGGTACCGATCTACTTCTCCAAATACATATCTTGG.

Retroviruses were produced by $\mathrm{CaCl}_{2}$ transfection of the $\mathrm{GP2}$-293 packaging cell line with the retroviral vectors encoding complex I genes and pVSV-G. Twelve hours after transfection, cells were washed and stimulated with $10 \mathrm{mM}$ sodium butyrate for $12 \mathrm{~h}$ before changing the medium. Retroviral supernatants were collected after $48 \mathrm{~h}$. Cells were transduced by $12 \mathrm{~h}$ incubation with the retroviral supernatant in the presence of $8 \mu \mathrm{g} / \mathrm{ml}$ polybrene. Puromycin, G-418 and hygromycin selection was begun $48 \mathrm{~h}$ after infection.

Effector-target killing assay. Target cells $\left(721.221,0.05 \times 10^{6}\right)$ in $100 \mu \mathrm{l}$ of medium (HBSS containing $1.55 \mathrm{mM} \mathrm{CaCl} 2,17.5 \mathrm{mM}$ glucose, $10 \mathrm{mM}$ HEPES, pH 7.4) were mixed with an equal volume of effector cells (YT-indy) at the indicated effector-to-target $(E / T)$ ratios and incubated at $37^{\circ} \mathrm{C}$ for the indicated times. The $5 \mathrm{x}$ loading buffer with $\beta$-mercaptoethanol was directly added to the mixture before SDS-PAGE and immunoblot. For caspase inhibition, target cells were pretreated for $15 \mathrm{~min}$ with $10 \mu \mathrm{M} \mathrm{z}$-VAD-fmk before incubation with effector cells. For calcein release assay, target cells were preloaded with $10 \mu \mathrm{M}$ Calcein AM (Life Technologies) for $30 \mathrm{~min}$, then washed three times and incubated with effector cells as previously for the indicated time. Specific killing were determined by monitoring the calcein released in the supernatant:

$\%$ Specific release $=100 \frac{\text { release }- \text { spontaneous release }}{\max \text { release }- \text { spontaneous release }}$

Generation of $\boldsymbol{\rho}^{\mathbf{0}}$ cells. K562 cells were cultured in DMEM supplemented with ethidium bromide $(250 \mathrm{ng} / \mathrm{ml})$, sodium pyruvate $(110 \mu \mathrm{g} / \mathrm{ml})$ and uridine $(50 \mu \mathrm{g} /$ $\mathrm{ml})$ for at least 1 month. Mitochondrial DNA was quantified by qPCR using primers specific for COX1 and normalized to nuclear DNA using primers for RNaseP.

Cell fractionation. Treated cells $\left(1 \times 10^{6}\right)$ were washed with PBS and resuspended in $100 \mu \mathrm{l}$ of cytosolic extraction buffer $(70 \mathrm{mM} \mathrm{KCl}, 137 \mathrm{mM} \mathrm{NaCl}$, $1.4 \mathrm{mM} \mathrm{KH}_{2} \mathrm{PO}_{4} \mathrm{pH} 7.2,4.3 \mathrm{mM} \mathrm{Na}_{2} \mathrm{HPO}_{4}, 250 \mathrm{mM}$ sucrose, $50 \mu \mathrm{g} / \mathrm{ml}$ D, protease inhibitors) and placed on ice for $5 \mathrm{~min}$. Cells were centrifuged at $1000 \times \mathrm{g}$ for $5 \mathrm{~min}$ and the supernatant was stored as the cytosolic fraction. The pellet was resuspended in $100 \mu \mathrm{l}$ of mitochondrial lysis buffer $(50 \mathrm{mM}$ Tris, pH 7.4, $150 \mathrm{mM}$ $\mathrm{NaCl}, 2 \mathrm{mM}$ EDTA, 2 mM EGTA, 2\% Triton X-100, 0.3\% NP-40, protease inhibitors). After 10 min of centrifugation at $10000 \times g$, the supernatant was kept as the mitochondrial-enriched fraction.

Quantification of GB uptake. Cells were washed in HBSS and resuspended in cell buffer (HBSS with $10 \mathrm{mM}$ HEPES, pH 7.4, 0.4\% BSA, $4 \mathrm{mM}$ $\mathrm{CaCl}_{2}$ ). GB, labeled with Alexa Fluor-647 using the Alexa Fluor-647 Labeling Kit from Life Technologies according to the manufacturer's protocol, was added to cells just before adding a sublytic dose of P. After $10 \mathrm{~min}$ at $37^{\circ} \mathrm{C}$, cells were extensively washed with $\mathrm{HBSS}$ at $4^{\circ} \mathrm{C}$ before flow cytometry analysis.

DNA laddering assay. Treated cells $\left(1.5 \times 10^{6}\right)$ were washed with cold PBS, resuspended in lysis buffer (10 mM Tris-HCl, pH 7.4, $10 \mathrm{mM}$ EDTA, 0.5\% SDS) and incubated for $10 \mathrm{~min}$ on ice. RNAse A $(100 \mu \mathrm{g} / \mathrm{ml})$ was added for $1 \mathrm{~h}$ at $37^{\circ} \mathrm{C}$, followed by the addition of $100 \mu \mathrm{g} / \mathrm{ml} \mathrm{PK}$ for $4 \mathrm{~h}$ at $50^{\circ} \mathrm{C}$. After adding $300 \mathrm{mM}$ sodium acetate, pH 5.2, DNA was precipitated with ethanol overnight at $-20^{\circ} \mathrm{C}$. The pellet obtained after centrifugation at $14000 \times g$ for 30 min was dissolved in TE buffer (10 mM Tris, pH 8.0, $1 \mathrm{mM}$ EDTA). DNA $(6 \mu \mathrm{g})$ was electrophoresed through $1.2 \%$ agarose gels containing $0.5 \mu \mathrm{g} / \mathrm{ml}$ ethidium bromide.

Isolated mitochondria assays. Mitochondria isolated from mouse liver as described ${ }^{51}$ were freshly prepared for all assays. Mitochondria $(2.5 \mathrm{mg} / \mathrm{ml}$ protein) in $40 \mu \mathrm{l}$ import buffer $(600 \mathrm{mM}$ sorbitol, $160 \mathrm{mM} \mathrm{KCl}, 20 \mathrm{mM}$ magnesium acetate, $4 \mathrm{mM} \mathrm{KH}_{2} \mathrm{PO}_{4}, 5 \mathrm{mM}$ EDTA, $5 \mathrm{mM} \mathrm{MnCl}$, $200 \mathrm{mM}$ HEPES, pH 7.2) were incubated with $\mathrm{GB}(450 \mathrm{nM})$ for $5 \mathrm{~min}$ at $37^{\circ} \mathrm{C}$ and $10 \mu$ of reactions were analyzed by immunoblot. For apoptogenic factor release experiments, mitochondria were incubated with $\mathrm{GB}(450 \mathrm{nM})$ alone or with $25 \mu \mathrm{g}$ of $\mathrm{S} 100$ for $1 \mathrm{~h}$ at $37^{\circ} \mathrm{C}$. After centrifugation at $8000 \times g$, supernatant and pellet were analyzed by immunoblot. For $\mathrm{O}_{2}$ consumption and electron microscopy experiments, mitochondria were purified as described..$^{52}$ Mitochondrial pellet was resuspended in respiration buffer $(150 \mathrm{mM}$ $\mathrm{KCl}, 10 \mathrm{mM}$ Tris/MOPS and $10 \mu \mathrm{M}$ ATP). Mitochondria $(400 \mu \mathrm{g})$ were transferred to a Clark electrode chamber to measure oxygen consumption. Succinate $(5 \mathrm{mM})$ or glutamate and malate ( 5 and $2.5 \mathrm{mM}$, respectively) were added, and 5 min later GB $(450 \mathrm{nM})$ was added. Oxygen consumption was recorded over $20 \mathrm{~min}$. Mitochondrial import assays were performed according to Mokranjac and Neupert. ${ }^{53}$ Fifty micrograms of mitochondria in the import buffer were incubated with $200 \mathrm{ng}$ of unlabeled or Alexa-647 GB for $15 \mathrm{~min}$ at $37^{\circ} \mathrm{C}$. Half of the reactions were treated with $50 \mu \mathrm{g} / \mathrm{ml}$ of PK for $15 \mathrm{~min}$ on ice to give the imported fraction. PK was inactivated with $5 \mu \mathrm{l}$ of $0.2 \mathrm{M} \mathrm{PMSF}$ and sample spun at $12000 \times \mathrm{g}$ for $15 \mathrm{~min}$. Pellets were resuspended in either PBS or $1 x$ SDS sample buffer for FACS and WB analysis, respectively. The second halves ware use as input. In some cases, mitochondria in SH buffer were preincubated with $0.4 \mu \mathrm{M}$ of valinomycin for $15 \mathrm{~min}$ to disrupt the $\Delta \Psi$ before carrying the import assay.

Respiratory complex in-gel activity. Mitochondria $(400 \mu \mathrm{g}$ in $40 \mu \mathrm{l}$ of import buffer) were treated with $450 \mathrm{nM}$ of GB for $5 \mathrm{~min}$ at $37^{\circ} \mathrm{C}$. The reaction was stopped by adding $3 \mu \mathrm{l}$ of $0.2 \mathrm{M}$ PMSF. After $5 \mathrm{~min}$ on ice, samples were spun for $30 \mathrm{~min}$ at $12000 \times \mathrm{g}$. Pellets were solubilized on ice for $15 \mathrm{~min}$ with $40 \mu \mathrm{l}$ of lysis buffer. For monomeric complex resolution, pellets were resuspended in LM buffer $(50 \mathrm{mM} \mathrm{NaCl}, 1 \mathrm{mM}$ EDTA, $50 \mathrm{mM}$ imidazole/ $/ \mathrm{HCl}, 2 \mathrm{mM}$ 6-aminohexanoic acid, pH $7.0,2 \%$ freshly prepared $L M)$. To resolve SCs, pellets were solubilized in D buffer (30 mM HEPES, pH 7.4, $150 \mathrm{mM}$ potassium acetate, 10\% glycerol and $5 \%$ freshly prepared D). Samples were spun for $20 \mathrm{~min}$ at $20000 \times \mathrm{g}$ at $4{ }^{\circ} \mathrm{C}$. Six microliters of $50 \%$ glycerol and $5 \mu \mathrm{l}$ of $5 \%$ Coomassie blue G-250 were added to the supernatant to give a detergent/dye mass ratio of 8 . Mitochondria ( $100 \mu \mathrm{g})$ were electrophoresed at $30 \mathrm{~V}$ for $30 \mathrm{~min}$ through native $3-13 \%$ gradient acrylamide gels using anode buffer (imidazole $25 \mathrm{mM}, \mathrm{pH}$ 7) and cathode buffer B (50 mM Tricine, pH 7, $7.5 \mathrm{mM}$ imidazole, $0.02 \%$ Coomassie blue G-250). Then, the cathode buffer B was replaced by cathode buffer A ( $50 \mathrm{mM}$ Tricine, pH 7.0, 7.5 mM imidazole, 0.002\% Coomassie blue G-250) and electrophoresis was continued at $80 \mathrm{~V}$ until the dye front reached the gel bottom. Complex I, IV and V were assayed as described. ${ }^{38}$ Briefly, gels were washed in distilled water before incubation at RT with the following solutions: Complex I solution - $2 \mathrm{mM}$ Tris- $\mathrm{HCl}$, pH 7.4, $0.1 \mathrm{mg} / \mathrm{ml} \mathrm{NADH,} 2.5 \mathrm{mg} / \mathrm{ml}$

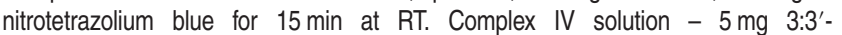
diamidobenzidine tetrahydrochloride dissolved in $9 \mathrm{ml}$ of $5 \mathrm{mM}$ phosphate buffer $(0.05 \mathrm{M}, \mathrm{pH} 7.4), 1 \mathrm{nM}$ catalase $(20 \mathrm{U} / \mathrm{ml}), 10 \mathrm{mg}$ Cyt $c$ and $750 \mathrm{mg}$ sucrose overnight at RT. Complex V solution - $35 \mathrm{mM}$ Tris, pH 7.8, $270 \mathrm{mM}$ glycine, $14 \mathrm{mM}$ $\mathrm{MgSO}_{4}, 0.2 \% \mathrm{~Pb}\left(\mathrm{NO}_{3}\right)_{2}, 8 \mathrm{mM}$ ATP and overnight at RT. Gels were washed in distilled water and scanned immediately. Complex III activity was assayed as described in Smet et al..$^{39}$ Briefly, gels were incubated in Complex III solution - 1STEP TMB-BLOT (Pierce, Thermo Scientific, Rockford, IL, USA) overnight at RT.

Spectrophotometric respiratory complex assay. Mitochondria $(60 \mu \mathrm{g}$ in $30 \mu \mathrm{l}$ of import buffer) were treated with $450 \mathrm{nM}$ of GB for $5 \mathrm{~min}$ at $37^{\circ} \mathrm{C}$. The reaction was stopped by adding $3 \mu \mathrm{l}$ of $0.2 \mathrm{M}$ PMSF. After $5 \mathrm{~min}$ on ice, the respiratory complex activities were measured according to Spinazzi et al. ${ }^{54}$ 
For complex I, the activity samples were subjected to three freeze-thraw cycles before assays.

Seahorse oxygen consumption. K562 and its $\rho^{0}$ cells were plated overnight at a density of 40000 cells per well in unbuffered assay medium supplemented with $25 \mathrm{mM}$ glucose, $1 \mathrm{mM}$ pyruvate, $4 \mathrm{mM}$ glutamine (same as their culture medium). One hour before measurement, medium was replaced for unbuffered assay medium at $37^{\circ} \mathrm{C}$ without $\mathrm{CO}_{2}$. Centrifugation of the plate at 1200 r.p.m. for $15 \mathrm{~min}$ allows suspension cells to attach for this assay. Measurement of intact cellular respiration was performed using the Seahorse XF24 analyzer (Seahorse Bioscience, North Billerica, MA, USA). Respiration was measured under basal condition, and in the presence of $1 \mu \mathrm{M}$ ATP synthase inhibitor oligomycin $0.75 \mu \mathrm{M}$ uncoupler FCCP, $1 \mu \mathrm{M}$ mitochondrial respiration complex I inhibitor Rotenone and $1 \mu \mathrm{M}$ mitochondrial respiration complex III inhibitor antimycin A.

Blue native-PAGE immunoblot. Mitochondria $(10 \mu \mathrm{g})$, resolved by BNGE as above, were transferred onto PVDF membranes using a semidry Hoefer transfer apparatus. Membranes were fixed in 100\% methanol before blocking and incubation at $4{ }^{\circ} \mathrm{C}$ overnight with primary antibodies.

Electron microscopy. Mouse liver mitochondria $(400 \mu \mathrm{g})$ in $40 \mu \mathrm{l}$ import buffer were treated with $450 \mathrm{nM} \mathrm{GB}$ with or without $25 \mu \mathrm{g} \mathrm{S} 100$ for $1 \mathrm{~h}$ at $37^{\circ} \mathrm{C}$. Samples were washed two times in $1 \times$ PBS and then fixed for 30 min at RT with $1.25 \%$ glutaraldehyde and $100 \mathrm{mM}$ sodium cacodylate. Embedding and staining were performed as in Scorrano et al. ${ }^{55}$ Thin sections were imaged on a Tecnai-20 electron microscope (Technai $20 \mathrm{FEI}$ Company, Eindhoven, Netherlands). The number of mitochondria with disrupted cristae junctions was counted in 1200 mitochondria for each condition.

\section{Conflict of Interest}

The authors declare no conflict of interest.

Acknowledgements. This work was supported by Ambizione SNSF PZOOP3 126710/1, ERC starting Grant ERC-2010-StG_20091118 and subsides from the Carlos and Elsie de Reuter Foundation and Schmidheiny Foundation. We

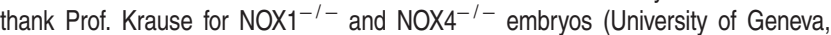
Geneva, Switzerland) and Olivier Dupont for technical assistance.

1. Chowdhury D, Lieberman J. Death by a thousand cuts: granzyme pathways of programmed cell death. Annu Rev Immunol 2008; 26: 389-420

2. Cullen SP, Adrain C, Luthi AU, Duriez PJ, Martin SJ. Human and murine granzyme B exhibit divergent substrate preferences. J Cell Biol 2007; 176: 435-444.

3. Andrade F, Roy S, Nicholson D, Thornberry N, Rosen A, Casciola-Rosen L. Granzyme B directly and efficiently cleaves several downstream caspase substrates: implications for CTLinduced apoptosis. Immunity 1998; 8: 451-460.

4. Kroemer G, Galluzzi L, Brenner C. Mitochondrial membrane permeabilization in cell death Physiol Rev 2007; 87: 99-163.

5. MacDonald G, Shi L, Vande Velde C, Lieberman J, Greenberg AH. Mitochondria-dependent and -independent regulation of Granzyme B-induced apoptosis. J Exp Med 1999; 189 131-144.

6. Sutton VR, Wowk ME, Cancilla M, Trapani JA. Caspase activation by granzyme B is indirect, and caspase autoprocessing requires the release of proapoptotic mitochondrial factors. Immunity 2003; 18: 319-329.

7. Waterhouse NJ, Sedelies KA, Browne KA, Wowk ME, Newbold A, Sutton VR et al. A central role for Bid in granzyme B-induced apoptosis. J Biol Chem 2005; 280: 4476-4482.

8. Goping IS, Barry M, Liston P, Sawchuk T, Constantinescu G, Michalak KM et al. Granzyme B-induced apoptosis requires both direct caspase activation and relief of caspase inhibition. Immunity 2003; 18: 355-365.

9. Alimonti JB, Shi L, Baijal PK, Greenberg AH. Granzyme B induces BID-mediated cytochrome $c$ release and mitochondrial permeability transition. J Biol Chem 2001; 276 6974-6982.

10. Kaiserman D, Bird CH, Sun J, Matthews A, Ung K, Whisstock JC et al. The major human and mouse granzymes are structurally and functionally divergent. J Cell Biol 2006; 175 $619-630$

11. Han J, Goldstein LA, Hou W, Froelich CJ, Watkins SC, Rabinowich H. Deregulation of mitochondrial membrane potential by mitochondrial insertion of granzyme $\mathrm{B}$ and direct Hax1 cleavage. J Biol Chem 2010; 285: 22461-22472.

12. Heibein JA, Barry M, Motyka B, Bleackley RC. Granzyme B-induced loss of mitochondria inner membrane potential (Delta Psi $\mathrm{m}$ ) and cytochrome $c$ release are caspase independent. J Immunol 1999; 163: 4683-4693.
13. Thomas DA, Scorrano L, Putcha GV, Korsmeyer SJ, Ley TJ. Granzyme B can cause mitochondrial depolarization and cell death in the absence of BID, BAX, and BAK. Proc Natl Acad Sci USA 2001; 98: 14985-14990.

14. Balsa E, Marco R, Perales-Clemente E, Szklarczyk R, Calvo E, Landázuri MO et al. NDUFA4 is a subunit of complex IV of the mammalian electron transport chain. Cell Metab 2012; 16: 378-386.

15. Ricci JE, Muñoz-Pinedo C, Fitzgerald P, Bailly-Maitre B, Perkins GA, Yadava N et al. Disruption of mitochondrial function during apoptosis is mediated by caspase cleavage of the p75 subunit of complex I of the electron transport chain. Cell 2004; 117: 773-786.

16. Martinvalet D, Dykxhoorn DM, Ferrini R, Lieberman J. Granzyme A cleaves a mitochondrial complex I protein to initiate caspase-independent cell death. Cell 2008; 133: 681-692.

17. Martinvalet D, Zhu P, Lieberman J Granzyme A induces caspaseindependent mitochondrial damage, a required first step for apoptosis. Immunity 2005; 22: 355-370.

18. Beresford PJ, Xia Z, Greenberg AH, Lieberman J. Granzyme A loading induces rapid cytolysis and a novel form of DNA damage independently of caspase activation. Immunity 1999; 10: 585-594.

19. Fan Z, Beresford PJ, Oh DY, Zhang D, Lieberman J. Tumor suppressor NM23-H1 is a granzyme A-activated DNase during CTL-mediated apoptosis, and the nucleosome assembly protein SET is its inhibitor. Cell 2003; 112: 659-672.

20. Martinvalet D, Thiery J. A novel caspase-independent apoptotic pathway triggered by ganzyme A]. Med Sci (Paris) 2008; 24: 901-903.

21. Kelso GF, Porteous CM, Coulter CV, Hughes G, Porteous WK, Ledgerwood EC et al. Selective targeting of a redox-active ubiquinone to mitochondria within cells: antioxidant and antiapoptotic properties. J Biol Chem 2001; 276: 4588-4596.

22. Sherwood S, Hirst J. Investigation of the mechanism of proton translocation by NADH: ubiquinone oxidoreductase (complex I) from bovine heart mitochondria: does the enzyme operate by a Q-cycle mechanism? Biochem J 2006; 400: 541-550.

23. Ngu LH, Nijtmans LG, Distelmaier F, Venselaar H, van Emst-de Vries SE, van den Brand MA et al. A catalytic defect in mitochondrial respiratory chain complex I due to a mutation in NDUFS2 in a patient with Leigh syndrome. Biochim Biophys Acta 2012; 1822: 168-175.

24. Pagniez-Mammeri H, Loublier S, Legrand A, Bénit $P$, Rustin $P$, Slama A. Mitochondrial complex I deficiency of nuclear origin I. Structural genes. Mol Genet Metab 2012; 105: $163-172$

25. Pagniez-Mammeri H, Rak M, Legrand A, Bénit P, Rustin P, Slama A. Mitochondrial complex I deficiency of nuclear origin II. Non-structural genes. Mol Genet Metab 2012; 105: 173-179.

26. Hirst J, Carroll J, Fearnley IM, Shannon RJ, Walker JE. The nuclear encoded subunits of complex I from bovine heart mitochondria. Biochim Biophys Acta 2003; 1604: 135-150.

27. Igarashi Y, Eroshkin A, Gramatikova S, Gramatikoff K, Zhang Y, Smith JW et al. CutDB: a proteolytic event database. Nucleic Acids Res 2007; 35: D546-D549.

28. Lapuente-Brun E, Moreno-Loshuertos R, Acín-Pérez R, Latorre-Pellicer A, Colás C, Balsa E et al. Supercomplex assembly determines electron flux in the mitochondrial electron transport chain. Science 2013; 340: 1567-1570.

29. Lazarou M, McKenzie M, Ohtake A, Thorburn DR, Ryan MT. Analysis of the assembly profiles for mitochondrial- and nuclear-DNA-encoded subunits into complex I. Mol Cell Biol 2007; 27: 4228-4237.

30. McKenzie M, Ryan MT. Assembly factors of human mitochondrial complex I and their defects in disease. IUBMB Life 2010; 62: 497-502.

31. Wei MC, Zong WX, Cheng EH, Lindsten T, Panoutsakopoulou V, Ross AJ et al. Proapoptotic BAX and BAK: a requisite gateway to mitochondrial dysfunction and death. Science 2001; 292: 727-730

32. Petrosillo G, Ruggiero FM, Paradies G. Role of reactive oxygen species and cardiolipin in the release of cytochrome $c$ from mitochondria. FASEB J 2003; 17: 2202-2208.

33. Petrosillo G, Ruggiero FM, Pistolese M, Paradies G. $\mathrm{Ca}^{2+}$-induced reactive oxygen species production promotes cytochrome $\mathrm{c}$ release from rat liver mitochondria via mitochondria permeability transition (MPT)-dependent and MPT-independent mechanisms: role of cardiolipin. J Biol Chem 2004; 279: 53103-53108

34. Kim JS, Lee JH, Jeong WW, Choi $\mathrm{DH}$, Cha $\mathrm{HJ}$, Kim do $\mathrm{H}$ et al. Reactive oxygen species-dependent EndoG release mediates cisplatin-induced caspase-independent apoptosis in human head and neck squamous carcinoma cells. Int J Cancer 2008; 122 : $672-680$.

35. Huai J, Vögtle FN, Jöckel L, Li Y, Kiefer T, Ricci JE et al. TNFalpha-induced lysosomal membrane permeability is downstream of MOMP and triggered by caspase-mediated NDUFS1 cleavage and ROS formation. J Cell Sci 2013; 126: 4015-4025.

36. Aguilo JI, Anel A, Catalán E, Sebastián A, Acín-Pérez R, Naval J et al. Granzyme B of cytotoxic $T$ cells induces extramitochondrial reactive oxygen species production via caspasedependent NADPH oxidase activation. Immunol Cell Biol. 2010; 88: 545-554.

37. Kaminski M, Kiessling M, Suss D, Krammer PH, Gulow K. Novel role for mitochondria: protein kinase Ctheta-dependent oxidative signaling organelles in activation-induced T-cell death. Mol Cell Biol 2007; 27: 3625-3639.

38. Nijtmans LG, Henderson NS, Holt IJ. Blue Native electrophoresis to study mitochondrial and other protein complexes. Methods 2002; 26: 327-334.

39. Smet J, De Paepe B, Seneca S, Lissens W, Kotarsky H, De Meirleir L et al. Complex III staining in blue native polyacrylamide gels. J Inherit Metab Dis. 2011; 34 741-747. 
40. Cogliati S, Frezza C, Soriano ME, Varanita T, Quintana-Cabrera R, Corrado M et al. Mitochondrial cristae shape determines respiratory chain supercomplexes assembly and respiratory efficiency. Cell 2013; 155: 160-171.

41. Murphy MP. How mitochondria produce reactive oxygen species. Biochem J 2009; 417: $1-13$.

42. Malassagne B, Ferret PJ, Hammoud R, Tulliez M, Bedda S, Trébéden $\mathrm{H}$ et al. The superoxide dismutase mimetic MnTBAP prevents Fas-induced acute liver failure in the mouse. Gastroenterology 2001; 121: 1451-1459.

43. Walch M, Dotiwala F, Mulik S, Thiery J, Kirchhausen T, Clayberger C et al. Cytotoxic cells kill intracellular bacteria through granulysin-mediated delivery of granzymes. Cell 2014; 157 : 1309-1323.

44. Sazanov LA, Hinchliffe P. Structure of the hydrophilic domain of respiratory complex I from Thermus thermophilus. Science 2006; 311: 1430-1436.

45. Dudkina NV, Eubel H, Keegstra W, Boekema EJ, Braun HP. Structure of a mitochondrial supercomplex formed by respiratory-chain complexes I and III. Proc Natl Acad Sci USA 2005; 102: 3225-3229.

46. Dudkina NV, Kouril R, Peters K, Braun HP, Boekema EJ. Structure and function of mitochondrial supercomplexes. Biochim Biophys Acta 2010; 1797: 664-670.

47. Lambert AJ, Brand MD. Inhibitors of the quinone-binding site allow rapid superoxide production from mitochondrial NADH:ubiquinone oxidoreductase (complex I). J Biol Chem 2004; 279: 39414-39420.
48. Lambert AJ, Brand MD. Superoxide production by NADH:ubiquinone oxidoreductase (complex I) depends on the $\mathrm{pH}$ gradient across the mitochondrial inner membrane. Biochem J 2004; 382: 511-517.

49. Frezza C, Cipolat S, Martins de Brito O, Micaroni M, Beznoussenko GV, Rudka T et al. OPA1 controls apoptotic cristae remodeling independently from mitochondrial fusion. Cell 2006; 126: 177-189.

50. Thiery J, Walch M, Jensen DK, Martinvalet D, Lieberman J. Isolation of cytotoxic T cell and NK granules and purification of their effector proteins. Curr Protoc Cell Biol 2010; (Chapter 3, Unit 3) 37.

51. Susin SA, Larochette N, Geuskens M, Kroemer G. Purification of mitochondria for apoptosis assays. Methods Enzymol 2000; 322: 205-208.

52. Frezza $\mathrm{C}$, Cipolat $\mathrm{S}$, Scorrano $\mathrm{L}$. Organelle isolation: functional mitochondria from mouse liver, muscle and cultured fibroblasts. Nat Protoc 2007; 2: 287-295.

53. Mokranjac D, Neupert W. Protein import into isolated mitochondria. Methods Mol Biol 2007; 372: $277-286$.

54. Spinazzi M, Casarin A, Pertegato V, Salviati L, Angelini C. Assessment of mitochondrial respiratory chain enzymatic activities on tissues and cultured cells. Nat Protoc 2012; 7: 1235-1246.

55. Scorrano L, Ashiya M, Buttle K, Weiler S, Oakes SA, Mannella CA et al. A distinct pathway remodels mitochondrial cristae and mobilizes cytochrome $c$ during apoptosis. Dev Cell 2002; 2 : $55-67$.

Supplementary Information accompanies this paper on Cell Death and Differentiation website (http://www.nature.com/cdd) 